\title{
Consortium of European Taxonomic Facilities (CETAF) best practices in electronic publishing in taxonomy
}

\author{
Laurence BÉNICHOU ${ }^{1, *}$, Isabelle GÉRARD ${ }^{2}$, Éric LAUREYS ${ }^{3} \&$ Michelle J. PRICE ${ }^{4}$ \\ ${ }^{1}$ Muséum national d'Histoire naturelle (MNHN), 57 rue Cuvier, 75005 Paris, France. \\ ${ }^{2}$ Royal Museum for Central Africa (RMCA), Leuvensesteenweg 13, 3080 Tervuren, Belgium. \\ ${ }^{3}$ Belgian Science Policy Office, 231 Avenue Louise, BE-1050 Brussels, Belgium. \\ ${ }^{4}$ Conservatoire et Jardin botaniques de la Ville de Genève (CJBG), chemin de l'Impératrice 1, \\ 1292 Chambésy-GE, Switzerland.
}
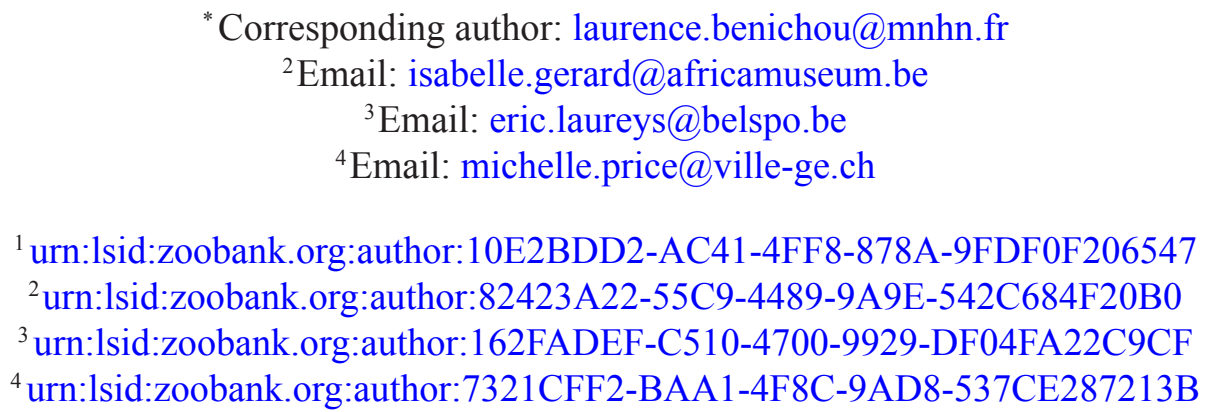

\begin{abstract}
In order to consider the effects of online publishing on the career of researchers, as well as to encourage both its recognition and its improved positioning within the field and beyond, the CETAF Membership organized two workshops during which specific questions about scientific publishing in taxonomy were addressed: authorship citation and Open Access. The present opinion paper is the result of those workshops held on 19 October 2016 in Madrid and on 4 October 2017 in Heraklion. The discussions were aimed at reconciling the requirements of the relevant nomenclatural codes with recommendations for best practices that are adapted to the evolving landscape of e-publishing. By evaluating the different policies of a range of journals regarding authorship citation, we were able to recognise the conflicting and incoherent practices related to the citation of taxon authorships; an issue that is important to clarify for scientific (explicit source), practical (findability of source) and reputational (citation index) reasons. A collective policy on authorship citation also fits into the wider challenge faced by researchers and institutions, whereby interoperability and traceability become key priorities, both for facilitating access to scientific resources and for generating metrics that accurately represent the activities and output of the community. Publications resulting from publicly-funded research should be considered as an essential part of the research process and there has been a strong move towards Open Access, which increases visibility, citability, innovation and impact. Diverse models of Open Access have appeared in scientific publishing but while they each promote free access to the end user, they are not always equitable for the authors and funders of the original research. Herein we formulate recommendations for the relevant research communities and outline the advantages behind adopting a collective strategy towards the issues of authorship citation and Open Access.
\end{abstract}

Keywords. E-publishing, CETAF, authorship citation, Open Access. 
Bénichou L., Gérard I., Laureys É. \& Price M.J. 2018. Consortium of European Taxonomic Facilities (CETAF) best practices in electronic publishing in taxonomy. European Journal of Taxonomy 475: 1-37. https://doi.org/10.5852/ejt.2018.475

\section{Introduction}

Scientific publications differ from magazines, journals or books aimed at a general audience in the fact that they publish original peer-reviewed research and have therefore been evaluated scientifically before publication. Most existing scientific journals are related to a particular field (science, technology, medicine, social sciences, humanities) and within each field they can also be highly specialized. Publishing research results in a scientific journal opens them up to the scrutiny of the scientific community and allows results to be archived for the purposes of citation and future referencing.

Journals may be published by learned societies, science academies or institutions, or they may be published independently via commercial companies. Generally, major commercial publishers specialize in editing, printing and distributing the journals that they produce, but some journals continue to function independently, under different operating models. Since the 1790s, exchange programmes between institutional libraries in natural history institutions have been the traditional way of disseminating taxonomic literature. Online availability and Open Access have had a strong impact on this tradition, and on how institutions may decide to manage and/or publish their own journals in the future.

Journals are increasingly available online, with some continuing to produce only print editions, and others offering both formats. Online dissemination does not, however, automatically mean Open Access.

When publishing in taxonomy there are specificities that should be taken into account, such as:

- Valid and effective publication: the description of a new species or a comparable nomenclatural act must be done in compliance with the relevant nomenclature codes. Five different codes regulate naming taxa: the International Code of Nomenclature of Bacteria; the International Code of Virus Classification and Nomenclature; the International Code of Nomenclature for Cultivated Plants; the International Code of Nomenclature for Algae, Fungi, and Plants; and the International Code of Zoological Nomenclature. We have focused herein on the two main codes used in natural history sciences, namely those for botany (Turland et al. 2018) and zoology (ICZN 1999, 2012).

- Accessibility and preservation of the content: the taxonomic revision of any given group, depending on the group, may take place periodically or remain outstanding for many years. To support taxonomy, all taxonomic acts must remain available and accessible through time.

Another critical issue in taxonomy publishing is the journal impact factor (JIF) of the Web of Knowledge (now owned by Clarivate Analytics). Used as a measure for determining the impact of a scientific journal, this metric is inappropriate for the field of taxonomy for several reasons, but mainly because the two-year period on which the impact factor is calculated is too short for citation returns in taxonomy. Even the five-year period on which the calculation may be based is often too short for taxonomy purposes because taxonomic works take time to be tested, adopted and integrated into scientific practice. In addition, the number of specialists studying a certain taxonomic group are, in many cases, so few and far between that citations are not significant.

Within this context, two workshop sessions held during CETAF meetings on 19 October 2016 in Madrid and 4 October 2017 in Heraklion addressed specific questions about scientific publishing in taxonomy:

-What are the requirements for publishing in taxonomy, and more specifically e-publishing in taxonomy?

- What are the practices for authorship citation in taxonomy?

- What are the different kinds of Open Access and which should be promoted in the field of taxonomy? 
BÉNICHOU L. et al., Best practices in electronic publishing in taxonomy

Regarding each question, the workshop aimed at sharing best practices on how to publish taxonomy by proposing a collective strategy and formulating recommendations. This paper summarizes the discussions and debates held during these workshops. The first part clarifies the requirements for publishing in taxonomy based on the latest nomenclatural codes. The second part addresses the issue of under-representation of taxonomic works by examining the way authors are credited when they describe a species and by proposing best practices to the taxonomic community to resolve this issue. The third part regards Open Access and focuses on how it is applied in the field of taxonomy. Lastly, the resulting set of recommendations discussed during the CETAF general meeting is proposed.

\section{Requirements for publishing and e-publishing in taxonomy}

Requirements for publishing nomenclatural novelties within taxonomy are set down within the International Code of Nomenclature for Algae, Fungi, and Plants (ICN) (Turland et al. 2018) and the International Commission for Zoological Nomenclature (ICZN) (ICZN 1999, 2012).

\section{ICN requirements for publication}

The Requirements for standard publication and e-publication were discussed at the XIX International Botanic Congress held in Shenzhen in July 2017, therefore this paper considers the accepted changes as they were reported in Taxon 66 (5) October 2017 and published in Turland et al. (2018).

The ICN is governed by guiding principles, outlined in Division 1 (Principles I-VI), that state the processes and premises of botanical and mycological nomenclature. Preamble 1 indicates "This Code aims at the provision of a stable method of naming taxonomic groups, avoiding and rejecting the use of names that may cause error or ambiguity or throw science into confusion."

Conditions of effective publication are stated in Chapter IV, Articles $29 \& 30$ (ICN 2018):

Art. 29.1: Publication is effected, under this Code, by distribution of printed matter (through sale, exchange, or gift) to the general public or at least to scientific institutions with generally accessible libraries. Publication is also effected by distribution on or after 1 January 2012 of electronic material in Portable Document Format (PDF; see also Art. 29.3 and Rec. 29A.1) in an online publication with an International Standard Serial Number (ISSN) or an International Standard Book Number (ISBN).

\section{ICN requirements for e-publication}

A nomenclatural novelty published in an e-publication format is considered effectively published within the ICN if it was distributed on or after 1 January 2012 and it is distributed in Portable Document Format (PDF) in an online publication with an ISSN or ISBN (Art. 29.1) with online defined in Art. 29.2 as “... accessible electronically via the World Wide Web."

The Recommendations state:

- 29A.1. Publication electronically in Portable Document Format (PDF) should comply with the PDF/A archival standard (ISO 19005).

- 29A.2. Authors of electronic material should give preference to publications that are archived and curated, satisfying the following criteria as far as is practical (see also Rec. 29A.1):

(a) The material should be placed in multiple trusted online digital repositories, e.g., an ISO-certified repository.

(b) Digital repositories should be in more than one area of the world and preferably on different continents.

For organisms considered as fungi, there is an additional requirement for valid publication: Art. F. 5.1 "In order to be validly published, nomenclatural novelties (Art. 6 Note 4) applied to organisms treated 
as fungi under this Code (Pre. 8; including fossil fungi and lichen-forming fungi) and published on or after 1 January 2013 must, in the protologue, include the citation of the identifier issued for the name by a recognized repository."

Specifications on what constitutes effectively published material are given in Article 30, including three articles that govern the content and issue of electronic publications, as follows:

30.2. An electronic publication is not effectively published if there is evidence within or associated with the publication that its content is merely preliminary and was, or is to be, replaced by content that the publisher considers final, in which case only the version with that final content is effectively published.

30.3. Content of an electronic publication includes that which is visible on the page, e.g., text, tables, illustrations, etc., but it excludes volume, issue, article, and page numbers; it also excludes external sources accessed via a hyperlink or URL (Uniform Resource Locator).

30.4. The content of a particular electronic publication must not be altered after it is effectively published. Any such alterations are not themselves effectively published. Corrections or revisions must be issued separately to be effectively published.

With the supporting recommendations:

30A.1. Preliminary and final versions of the same electronic publication should be clearly indicated as such when they are first issued. The phrase "Version of Record" should only be used to indicate a final version in which the content will not change.

30A.2. To facilitate citation, final versions of electronic publications should contain final pagination.

30A.3. Authors and editors are strongly recommended to include page numbers on the actual pages of publications, such that if electronic publications are printed, these page numbers are visible.

30A.4. It is strongly recommended that authors avoid publishing nomenclatural novelties in ephemeral printed matter of any kind, in particular printed matter that is multiplied in restricted and uncertain numbers, in which the permanence of the text may be limited, for which effective publication in terms of number of copies is not obvious, or that is unlikely to reach the general public. Authors should also avoid publishing nomenclatural novelties in popular periodicals, in abstracting journals, or on correction slips.

30A.5. To aid availability through time and place, authors publishing nomenclatural novelties should give preference to periodicals that regularly publish taxonomic work, or else they should send a copy of a publication (printed or electronic) to an indexing centre appropriate to the taxonomic group. When such publications exist only as printed matter, they should be deposited in at least ten, but preferably more, generally accessible libraries throughout the world.

30A.6. Authors and editors are encouraged to mention nomenclatural novelties in the summary or abstract, or list them in an index in the publication.

\section{ICZN requirements for publication}

Preamble: The objectives of the Code are to promote stability and universality in the scientific names of animals and to ensure that the name of each taxon is unique and distinct. 
BÉNICHOU L. et al., Best practices in electronic publishing in taxonomy

Criteria to be met to constitute a published work are indicated in Art. 8 (ICZN 2012):

8.1. Criteria to be met. A work must satisfy the following criteria:

8.1.1. it must be issued for the purpose of providing a public and permanent scientific record,

8.1.2. it must be obtainable, when first issued, free of charge or by purchase, and

8.1.3. it must have been produced in an edition containing simultaneously obtainable copies by a method that assures

8.1.3.1. numerous identical and durable copies (see Article 8.4), or

8.1.3.2. widely accessible electronic copies with fixed content and layout.

Example: PDF/A (Portable Document Format Archive), described by ISO Standard 19005-1:2005, is a file format that allows content and layout to be preserved unchanged.

Recommendation 8B: Minimum edition of printed works. A work on paper should be issued in a minimum edition of 25 copies, printed before any is distributed.

\section{ICZN requirements for e-publication}

To be considered published according to Article 8.5 (ICZN 2012), a work issued and distributed electronically must:

- have been issued after 2011

- have the date of publication stated in the work itself

- be registered in Zoobank and contain the evidence of such registration (LSID of the publication or of the new name must be indicated in the work itself). In Zoobank, the entry must give the name and internet address of an organisation other than the publisher that is intended to permanently archive the work in a manner that preserves the content and layout, and is capable of doing so. The ISSN or ISBN of the publication must be registered in the Zoobank entry.

With the supporting recommendations:

[Rec. 8A] ensure wide dissemination, by publishing in appropriate scientific journals or well-known monographic series

[Rec. $8 \mathrm{C}$ ] electronic works should be structured to allow automated indexing and data extraction and should include actionable links to external resources (such as embedded hyperlinks to records in the Official Register of Zoological Nomenclature), where appropriate

[Rec. $8 D$ ] content is immutable once published

[Rec. $8 E]$ public accessibility and permanent archiving are strongly recommended and taxonomic information should be permanently conserved in or by libraries that make their holdings publicly accessible

[Rec. $8 H]$ multiple archiving is encouraged in organizations that should have permanent or irrevocable license to make a work accessible should the publisher no longer do so

\section{Practical minimal recommendation to authors}

Publish in a journal with an ISSN archived in a LOCKSS system, which is an open-source libraryled digital preservation system built on the principle that 'lots of copies keep stuff safe". The journal should also, in zoology and mycology, accommodate Zoobank or MycoBank registrations and archive the articles in PDF/A. Regarding Botany, name registration is currently governed by Article 42 (Turland et al. 2018), with ongoing discussions being held within the IAPT Special Committee on Registration. 


\section{Authorship citation}

Both the main nomenclatural codes state when, and under which circumstances, the authorship of a new name or newly recombined name should be given. The authorship refers to the publication in which the author validly and effectively proposed the new name or recombined it or changed its rank. "Taxonomists gained credit for their discoveries and conclusions by having their names appended to taxonomic binomials" (Seifert et al. 2008). The authorship of a taxonomic name is thus considered by taxonomists as a bibliographic reference as it refers to the original publication in which the name was described, as well as the scientific concept behind that name. Yet these references are not considered to be valid citations by the Web of Science (now run by Clarivate Analytics) because they are not presented in a format that would justify their inclusion in the reference section of the article. Indexable citations are needed in taxonomy to (1) explicitly indicate the reference of the original description of a taxon and thus facilitate the examination of all sources used by the author, and (2) raise the h-index of taxonomists and the journal impact factor of taxonomic journals. For this study, we decided to perform a review of what is stated on authorship in the two main codes of nomenclature concerned, before exploring the different formats and rules regarding citation in taxonomic journals. Finally, the CETAF working session raised several issues that are discussed herein, and which needed to be explored in more detail before agreeing on a set of recommendations.

\section{ICN statement on authorship}

In the ICN (Turland et al. 2018) chapter 6 on citation, five articles (46-50) and a series of recommendations are dedicated to author citation, and section 2 contains seven specific recommendations (50A-G). The main premise of the articles and recommendations is that a name of a new taxon is attributed to the author(s) who described it in the published work (see Art. 46.2). When names are recombined (Art. 49.1) or change rank, the author citation is composed of the author(s) of the basionym, given in parentheses, followed by the author(s) of the name itself, e.g., Medicago polymorpha var. orbicularis L. (Sp. Pl.: 779. 1753) when raised to the rank of species becomes M. orbicularis (L.) Bartal. (Cat. Piante Siena: 60. 1776).

Some common practices are detailed in the notes contained in the Code, under each article. For instance, the use of "in" to differentiate the authorship of the name from the authorship of the publication in which it is published is stated in a note after Art. 46.1:

Note 2. When authorship of a name differs from authorship of the publication in which it was validly published, both are sometimes cited, connected by the word "in". In such a case, "in" and what follows are part of a bibliographic citation and are better omitted unless the place of publication is being cited.

The abbreviation of author names is standard practice in botany and mycology, with the way they should be abbreviated outlined in the Code (Rec. 46A, Note 1). Although this practice remains usual, it is by no mean mandatory:

Rec. 46A. Note 1. Brummitt \& Powell's Authors of plant names (1992) provides unambiguous standard forms for a large number of authors of names of organisms in conformity with this Recommendation. These standard forms, updated as necessary from the International Plant Names Index (www.ipni. org) and Index Fungorum (www.indexfungorum.org), have been used for author citations throughout this Code, albeit without additional spacing.

\section{ICZN statement on authorship}

In chapter 11 (ICZN 1999), authorship and citation of names of authors are covered in articles 50 and 51. Article 50 states that "the author of a name or nomenclatural act is the person who first publishes it". 
BÉNICHOU L. et al., Best practices in electronic publishing in taxonomy

As in botany, authorship of the original name remains unaffected by changes in rank or combination of the name.

Art. 51.2 defines the form of the citation of authorship:

"the name of an author follows the name of the taxon without any intervening mark of punctuation, except in changed combinations as provided in Article 51.3" [which states the use of parentheses around authors' names (and dates) in changed combinations], e.g., Limax ater Linnaeus, 1758 should be cited as Arion ater (Linnaeus, 1758) when the species is transferred to the genus Arion.

Even if Art. 51.1 states that the use of names of authors is optional, citation of author and date are strongly recommended:

"Art. 51.1. Optional use of names of authors. The name of the author does not form part of the name of a taxon and its citation is optional, although customary and often advisable".

"Recommendation 51A. Citation of author and date. The original author and date of a name should be cited at least once in each work dealing with the taxon denoted by that name. This is especially important in distinguishing between homonyms and in identifying species-group names which are not in their original combinations. If the surname and forename(s) of an author are liable to be confused, these should be distinguished as in scientific bibliographies."

"Recommendation 22A.1. Citation of date. It is strongly recommended that the date of publication (and the authorship; see Article 50) of a name be cited at least once in a work which deals with a taxon. This is particularly important for homonyms and for species-group names not in their original combinations."

Contrary to the practices in botany and mycology, the indication of the authorship of recombination or changes in rank is not a common practice (except in parasitology). Recommendation $51 \mathrm{G}$ indicates the way it should be written, if desired:

"Recommendation 51G. Citation of person making new combination. If it is desired to cite both the author of a species-group nominal taxon and the person who first transferred it to another genus, the name of the person forming the new combination should follow the parentheses that enclose the name of the author of the species-group name (and the date, if cited; see Recommendation 22A.3)", “e.g., Methiolopsis geniculata (Stål, 1878) Rehn, 1957”.

\section{Common authorship citation and bibliographic practices in taxonomic journals}

Most journals agree on how to cite an author (and a date in zoology), after the scientific name. The date of the nomenclatural novelty is, however, problematic nowadays with e-journals that publish papers online first and then group them in print issues afterwards. When the e-publication is code-compliant, the valid date for the nomenclatural act remains the date on which the paper was published online, even if the pagination numbering and issue number are only provided when the articles are grouped within a print issue. To refer to the exact page number of the print publication, we strongly recommend to explicitly indicate the date of the printed publication and the date of the nomenclatural availability, such as for instance: Niparaya Zamora-Silva A. \& Malaquias M.A.E., 2017 has been described in ZamoraSilva A. \& Malaquias M.A.E. (2018 [nomenclatural availability: 2017]). Molecular phylogeny of the Aglajidae head-shield sea slugs (Heterobranchia: Cephalaspidea): new evolutionary lineages revealed and proposal of a new classification. Zoological Journal of the Linnean Society 183 (1): 1-51. Codecompliant early view published online 1 November 2017; print version published 8 May 2018. https://doi.org/10.1093/zoolinnean/zlx064. 
The strict reproduction by the publisher of the online version and the print version (pagination and issue number included) would avoid such confusion. This recommendation has been followed by the MNHN journals that have recently switched to online publication (Zoosystema, Adansonia, Geodiversitas): the online version provides final pagination number and issue number and the date of publication (online) is indicated within the paper itself.

However, the problem that might occur is also whether the authorship citations, as treated in the journals, constitute a bibliographic reference or not, and thus whether it should be cited or not in the bibliographic references section. Examination of the practices in different taxonomic journals shows that each of them has its own rules (or, on the contrary, lacks rules on this matter) regarding the bibliographic treatment of authorship citations. These inconsistent practices and the confusion they generate have already been underlined and debated in the taxonomy community (Werner 2006; Seifert et al. 2008), especially amongst botanists. Indeed, when scientific names of species are mentioned in papers, more often than not, the author of the original description of the species does not appear or is only cited following taxon field standards (taxon-author combination, author name abbreviated forms). In these cases, the original publication does not appear in the references section, and thus is not considered as a valid citation for the journal impact factor calculation.

Seifert et al. (2008) published an opinion paper, putting forward appropriate practices for citation of authorship of scientific names or taxonomic descriptions, called "Appropriate Citation of Taxonomy" or "ACT", which aimed to improve the impact factor of taxonomic journals. According to these authors, appropriate citation of taxonomy should be applied each time a taxonomic concept is used, to credit the authors of the scientific names with a full entry in the bibliographic references. To ensure that this concept was respected by the journals, the authors suggested that formal citation should be added in a format that ensures its inclusion as a bibliographic reference. For studies employing many names (e.g., extensive checklists), sequences, or specimens, it may not always be possible to cite every source paper without extending the reference list beyond the length tolerated by editors. In such cases, the authors suggested that an arbitrary value - e.g., five names, sequences or specimens - could be used as a guide to determine which papers are to be cited.

It has been suggested previously that citing authorship of new descriptions would have a positive influence on the impact factor issue in taxonomy (Werner 2006). However, this was without taking into consideration the fact that citations of taxonomic articles take time to happen, and that the citation life of a taxonomic paper lasts decades or even centuries, rather than the shorter period of months or years used to calculate the metric. It has been shown that it may take an average of 21 years between the discovery and the description of new species (Fontaine et al. 2012), and an average of 43 years to synonymize a name (Solow et al. 1995). Taxonomic journals typically have a low citation rate during the two-year period used to calculate the impact factor, and therefore do not score well using this measure, regardless of the citation technique.

More recently, Wägele et al. (2011) expressed similar concerns to those of Werner (2006) and Seifert et al. (2008) and proposed a similar solution. They argued that there are strong discrepancies between the use of species names in scientific publications and citations of original authors. They proposed that "whenever a species name is used, the author(s) of the species hypothesis be included and the original literature source cited, including taxonomic revisions and identification literature". Wägele et al. (2011) approved of the practice of journals) that include the authorship citation in the references cited.

However, this practice is not agreed upon by all taxonomists. Meier (2017) explained that he is "against mechanically citing original species descriptions" because "it conflates taxon concepts (species delimitation) and species naming". From his point of view, "publications should be cited when they 
BÉNICHOU L. et al., Best practices in electronic publishing in taxonomy

contain significant scientific background information or support an argument in a manuscript". Kottelat (2015) also considers that the citation of taxon authorship should not demonstrate ownership of the name to enhance the author's reputation, but that this practice serves only as a bibliographic tool and therefore taxonomic works should logically include a full bibliographic reference for each name. However, he recommends limiting this practice to taxonomic works and avoiding the use of names of authors in nontaxonomic literature.

Considering these issues, the goals of the workshop were to:

- Identify the common practices in well-known journals publishing taxonomy, even if ideally a more comprehensive and comparative study of all journals published by CETAF members should be conducted;

- Identify what is at stake in improving the citation of taxon or nomenclature novelty authorship in scientific publications;

- Discuss and conceive best practices that could be adopted to improve authorship citation in taxonomy, as well as the facilities/tools that could be developed to help doing it;

- Consider the metrics most commonly used to evaluate research, from the perspective of researchers in taxonomy.

First, we identified and classified the common practices in well-known taxonomy journals. In order to have an overview of common practices, we selected a representative total sample of 25 journals from different taxonomic fields, most of which were accessed thanks to the MNHN Library online subscriptions. We chose ten journals in botany, ten in zoology and five in palaeontology, considering that palaeontology journals often follow the practices of either botanical or zoological journals, according to the group targeted, e.g., palaeobotany or palaeozoology (see Tables 1-3).

By studying the instructions to authors of these journals, we noticed that guidelines for taxon authorship citation were more detailed but more variable for botany than those for zoology. Indeed, the instructions to authors from most botanical journals are more explicit on the topic and describe more precisely both their rules regarding authorship citation and the subsequent inclusion of the work under the bibliographic references.

The journals were classified according to their level of precision into three different groups: (Group 1) journals whose instructions to authors indicate that the authorship should be cited and referenced in the bibliographic section; (Group 2) those in which it is explicitly instructed not to list the references associated with the authorship of a taxon, and; (Group 3) journals in which nothing specific is mentioned regarding the way in which taxon authorship should be referenced or not, which most of the time leads to the application of one of the above-stated rules, or leads to confusion. Tables 1-3 compile all of the selected journals and give extracts of their instructions to authors. In each case, some examples are provided to illustrate the practices.

\section{Group 1: Taxon authorship cited and referenced in the bibliographic section}

Most of the journals selected in this group (Table 1) have clear and precise instructions to their authors regarding the way taxon authorship must be cited and listed in the bibliographic section. Their instructions to authors specifically indicate that all references, including when exclusively used in taxonomic treatment, must be provided in the bibliography.

The group is predominantly represented in botany by five out of the ten journals selected (PhytoKeys, Plant Ecology and Evolution, Phytotaxa, Blumea and Willdenowia). 
Table 1 (continued on next page). Journals studied with extracts of their instructions to authors concerning taxon authorship citation. Group 1: Cited and referenced.

\begin{tabular}{|c|c|c|c|}
\hline Field & Journal title & Publisher & Extracts from Instructions for Authors \\
\hline Botany & Willdenowia & $\begin{array}{l}\text { Botanic Garden } \\
\text { and Botanical } \\
\text { Museum Berlin }\end{array}$ & $\begin{array}{l}\text { All bibliographical references quoted in the text, and only } \\
\text { those, are listed at the end of the manuscript, under the } \\
\text { heading References [...]. This also applies to references } \\
\text { quoted in an abbreviated way in the synonymy of } \\
\text { taxa; but in papers with very many such references, this } \\
\text { should apply only to recent references and to those } \\
\text { citing numerous names, in order to avoid an unacceptable } \\
\text { expansion of the references section. }\end{array}$ \\
\hline Botany & $\begin{array}{l}\text { Plant Ecology } \\
\text { and Evolution }\end{array}$ & $\begin{array}{l}\text { Botanic Garden } \\
\text { Meise }\end{array}$ & $\begin{array}{l}\text { All references cited in text (also when exclusively used } \\
\text { in the bibliographies of taxa in a taxonomic treatment) } \\
\text { are provided in the References section and vice versa }\end{array}$ \\
\hline Botany & Phytotaxa & Magnolia Press & $\begin{array}{l}\text { Citation of author names: Author abbreviations are seldom } \\
\text { used (generally only for basionym authors and new taxa } \\
\text { proposed in the manuscript); they are generally cited } \\
\text { fully in the references. This means that the name is not } \\
\text { abbreviated but the surname is written in full, followed } \\
\text { in brackets by the year of publication, a colon, and the } \\
\text { page number of the page where the name was published. } \\
\text { This is treated as a normal citation, and thus the full } \\
\text { article in which the species was published has to be } \\
\text { cited in the references. (Include full title of the article, } \\
\text { full journal title and full-page range.) This is obligatory } \\
\text { for all taxonomic articles and articles in which fewer than } \\
30 \text { taxa are mentioned. In articles that deal with a larger } \\
\text { number of species (such as ecological or phylogenetic } \\
\text { studies or checklists) this is not encouraged because it is } \\
\text { impractical. If uncertain, please contact an editor about this } \\
\text { matter. Author abbreviations (strictly following IPNI) are } \\
\text { only used in larger monographs and checklists, but even } \\
\text { in these articles names in introductions and running text } \\
\text { are properly cited in the references. Taxon author names } \\
\text { should be cited only once, when the taxon/species first } \\
\text { appears in the text. Phytotaxa aims to have all taxonomic } \\
\text { sources cited included in the reference section. Citation } \\
\text { of species authors is as follows: - Hymenophyllopsis } \\
\text { asplenioides A.C.Sm. in Gleason (1931: } 302 \text { ). Smith is } \\
\text { abbreviated here because it is published in Gleason, which } \\
\text { is the proper article to cite. }\end{array}$ \\
\hline Botany & Phytokeys & Pensoft & $\begin{array}{l}\text { Authors are encouraged to cite in the References list } \\
\text { the publications of the original descriptions of the taxa } \\
\text { treated in their manuscript. }\end{array}$ \\
\hline Palaeontology & $\begin{array}{l}\text { Journal of } \\
\text { Paleontology }\end{array}$ & $\begin{array}{l}\text { Cambridge } \\
\text { University Press } \\
\text { for the } \\
\text { Paleontological } \\
\text { Society }\end{array}$ & $\begin{array}{l}\text { Provide taxonomic assignment for each genus/species at } \\
\text { the Family level or higher (with authorship and date. } \\
\text { and their corresponding entries in the References } \\
\text { section). Insert one blank line before the list. }\end{array}$ \\
\hline
\end{tabular}


Table 1 (continued).

\begin{tabular}{|c|c|c|c|}
\hline Field & Journal title & Publisher & Extracts from Instructions for Authors \\
\hline Botany & Blumea & $\begin{array}{l}\text { Naturalis } \\
\text { Biodiversity } \\
\text { Center }\end{array}$ & $\begin{array}{l}\text { Citations in synonymy blocks should include author and } \\
\text { year only, as follows: Hemarthria longiflora (Hook.f.) } \\
\text { A.Camus (1922) } 380 \text { - Rottboelia longiflora Hook.f. } \\
\text { (1869) 154. The full citation, including titles of papers } \\
\text { book titles, journal names, etc., must be added to } \\
\text { 'References' in the format that is used in that section. } \\
\text { Please note that exceptionally, the reference to a basionym } \\
\text { for a new combination should include a "full and direct } \\
\text { reference" (ICBN art. 33.4) as follows: Friesodielsia } \\
\text { ovalifolia (Ridl.) I.M.Turner, comb. Nov. - Melodorum } \\
\text { ovalifolium Ridl., Bull. Misc. Inform. Kew 1912: } 387 \text {. For } \\
\text { both authors and journals Blumea follows the standard } \\
\text { abbreviations used by IPNI (www.ipni.org). These are } \\
\text { also available in R.K. Brummitt \& C.E. Powell (eds.) } \\
\text { 'Authors of Plant Names' (APN), Royal Botanic Gardens, } \\
\text { Kew, and in 'Botanico-Periodicum-Huntianum' (BPH). } \\
\text { But note that the use of abbreviations in the References } \\
\text { sections is strongly discouraged! }\end{array}$ \\
\hline Palaeontology & Geodiversitas & MNHN & $\begin{array}{l}\text { Each systematic description should be arranged as follows: } \\
\text { name of the taxon with author and date, original } \\
\text { reference of the description... Every taxon name cited } \\
\text { in the text should be followed, when first mentioned in } \\
\text { the text, in the résumé/abstract and in the captions of the } \\
\text { figures, by author(s) and date of description. }\end{array}$ \\
\hline $\begin{array}{l}\text { Zoology/ } \\
\text { Botany }\end{array}$ & $\begin{array}{l}\text { European } \\
\text { Journal of } \\
\text { Taxonomy }\end{array}$ & EJT consortium & $\begin{array}{l}\text { Each taxon account should, at least, include the following } \\
\text { items in the order listed: } \bullet \text { accepted taxon name with } \\
\text { author and year of description, } \bullet \text { list of synonymies, with } \\
\text { full references to cited papers, including figures (see } \\
\text { format below). }\end{array}$ \\
\hline Zoology & Zoosystema & MNHN & $\begin{array}{l}\text { Each systematic description should be arranged as follows: } \\
\text { name of the taxon with author and date, original } \\
\text { reference of the description... Every taxon name cited } \\
\text { in the text should be followed, when first mentioned in } \\
\text { the text, in the résumé/abstract and in the captions of the } \\
\text { figures, by author(s) and date of description. }\end{array}$ \\
\hline Zoology & $\begin{array}{l}\text { Journal of } \\
\text { Natural } \\
\text { History }\end{array}$ & Taylor and Francis & $\begin{array}{l}\text { On occasions where a synonymy is supplied, this should } \\
\text { be ranged left, and placed below with a line space after } \\
\text { species name: Adeonella calveti Canu and Bassler, } \\
\text { 1930: } 68 \text {, pl. } 10 \text {, figs. } 1-4 \text { Please include all taxonomic } \\
\text { authorities in the reference list. }\end{array}$ \\
\hline Zoology & Malacologia & $\begin{array}{l}\text { Institute of } \\
\text { Malacologia } \\
\text { (LS hosted by } \\
\text { Field Museum, } \\
\text { Chicago) }\end{array}$ & $\begin{array}{l}\text { In systematic papers, synonymies should not give } \\
\text { complete citations but should relate by authors, date } \\
\text { and page to the Literature Cited section. }\end{array}$ \\
\hline
\end{tabular}


The rule on taxon authorship citation (Fig. 1) is clearly defined in most journals, except for PhytoKeys which leaves it up to the author(s) to comply with the rule or not. Indeed, the journal's guidelines mention that "Authors are encouraged to cite in the References list the publications of the original descriptions of the taxa treated in their manuscript". As far as we could check by consulting random articles published in PhytoKeys, this recommendation (and more specifically the extent of its application) has proved to be unclear for the authors themselves. Thus, some authors have considered that the references of synonyms are not to be cited in the reference list (Fig. 2), whereas others have reported all references cited in their text, including synonymy and original descriptions, under the bibliographic section (Fig. 3).

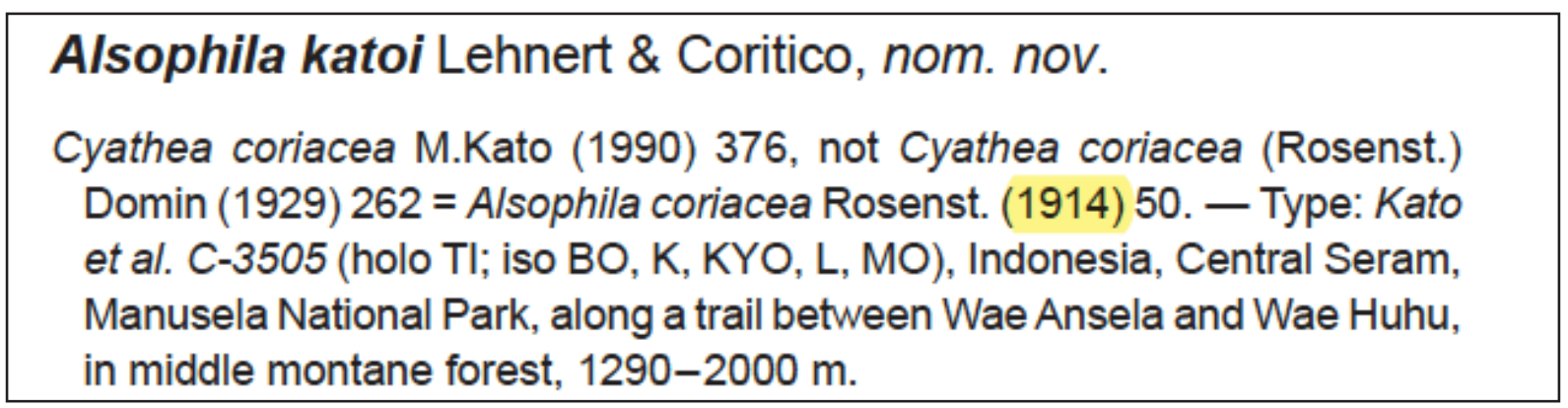

Fig. 1. The reference highlighted in yellow is listed under the references section, even though it has not been cited anywhere else in the article (Coritico et al. 2017).

\begin{tabular}{|c|c|}
\hline Taxonomic treatment & In text citation 4 \\
\hline \multirow{2}{*}{$\begin{array}{l}\text { The Elaeagnifolium clade of Solanum, sensu Stern et al. (2011) and Wahlert et al. } \\
\text { (2014) }\end{array}$} & $\begin{array}{l}\text { Wapshere AJ (1988) Prospects for the biological control of silverleaf } \\
\text { nightshade in Australia. Australian Journal of Agricultural Research 39: } \\
\text { 187-197. https://doi.org/10.1071/AR9880187 }\end{array}$ \\
\hline & Search via ReFindit \\
\hline $\begin{array}{l}\text { Solanum section Leprophora Dunal, Hist. Solanum 125, 181. 1813. Type species. S. elaeagnifolium Cav. } \\
\text { Solanum ellipticum species group sensu Whalen (1989), S. elaeagnifolium only, excl. type. }\end{array}$ & $\begin{array}{l}\text { Whalen MD (1979) Taxonomy of Solanum section Androceras. Gentes } \\
\text { Herbarum 11: } 359-426 \text {. }\end{array}$ \\
\hline Solanum vespertilio group sensu Whalen (1989), S. houstonii only [as S. tridynamum], excl. type. & In text citation , $\quad$ Search via ReFindit \\
\hline \multirow{2}{*}{$\begin{array}{l}\text { Solanum section Lathyrocarpum G.Don, Series } 4 \text { Nee (1999). Type species: S. elaeagnifolium Cav. (incl. } \\
\text { also S. hindsianum, S. houstonii [as S. tridynamum]). }\end{array}$} & $\begin{array}{l}\text { Whalen MD (1984) Conspectus of species groups in Solanum subgenus } \\
\text { Leptostemonum. Gentes Herbarum 12: 179-282. }\end{array}$ \\
\hline & Search via ReFindit \\
\hline $\begin{array}{l}\text { Description } \\
\text { Shrubs, sometimes rhizomatous, armed or unarmed. Stems terete, pubescent with multangulate, } \\
\text { porrect-stellate or lepidote trichomes, sometimes glabrescent. Sympodial units difoliate or occasionally }\end{array}$ & $\begin{array}{l}\text { Whalen MD, Costich DE (1986) Andromonoecy in Solanum. In: D'Arcy WG } \\
\text { (Ed). Solanaceae: biology and systematics. Columbia University Press, New } \\
\text { York, 284-302. }\end{array}$ \\
\hline trifoliate or plurifoliate, not geminate. Leaves simple to shallowly lobed to occasionally somewhat & Search via ReFindit \\
\hline
\end{tabular}

Fig. 2. Here, "Whalen (1989)" is cited in the taxonomic treatment but not listed in the references section (Knapp et al. 2017).

\begin{tabular}{|c|c|c|c|c|c|c|c|}
\hline \multirow{2}{*}{$\begin{array}{l}\text { Iconella anassae (Cholnoky) Cocquyt \& R. Jahn, comb. nov. } \\
\equiv \text { Surirella anassae Cholnoky in Oesterr. Bot. Z. 104: 84, fig. 278-279. } 1957 .\end{array}$} & \multirow{2}{*}{$\begin{array}{c}\text { Contents } \\
\text { Figs }\end{array}$} & \multicolumn{2}{|c|}{ Article info } & Citation & Metrics & Comment & \multirow[t]{2}{*}{ Related } \\
\hline & & Map & Taxa & Refs & Cited & & \\
\hline $\begin{array}{l}\text { Lectotype } \\
\text { (designated by Cocquyt et al. 2017). UNWH NIWR 186/3707 "Tugela Village, Nkunzini”. }\end{array}$ & \multicolumn{7}{|c|}{$\begin{array}{l}\text { Cholnoky BJ (1957) Neue und seltene Diatomeen aus Afrika III. Diatomeen } \\
\text { aus dem Tugela-Flußsystem, hauptsächlich aus den Drakensbergen in Natal. } \\
\text { Österreichische Botanische Zeitschrift 104: 25-99. https://doi.org/10.1007 } \\
\text { /BF01289120 }\end{array}$} \\
\hline
\end{tabular}

Fig. 3. Contrary to the example in Fig. 2, and despite it being published in the same journal, here "Cholnoky 1957" is cited only in the taxonomic treatment (and nowhere else in the text) and referenced under the bibliographic section (Jahn et al. 2017). 
BÉNICHOU L. et al., Best practices in electronic publishing in taxonomy

For all the other journals in Group 1, the rules on taxon authorship citation are precisely and clearly defined, and thus are to be strictly followed by the authors (see example in Fig. 1). No exceptions were found when browsing recently published issues. In order not to overload the references section, some journals have chosen to include only recent or significant citations. By limiting the citation to recent references (Fig. 4), the journals aim to avoid long bibliographic lists that take up space and are of limited use for journal impact factor purposes. However, what is considered 'recent' in taxonomic terms remains to be defined.

The most common practice in zoological journals is to formally cite the author in an unambiguous way so it can be listed as a reference (Fig. 5b). Indeed, in most of the cases, it is sufficient to indicate the page number on which the species was first described to consider it as a bibliographic reference and to cite it under the references section.

\begin{tabular}{|c|}
\hline Nomenclature \\
\hline 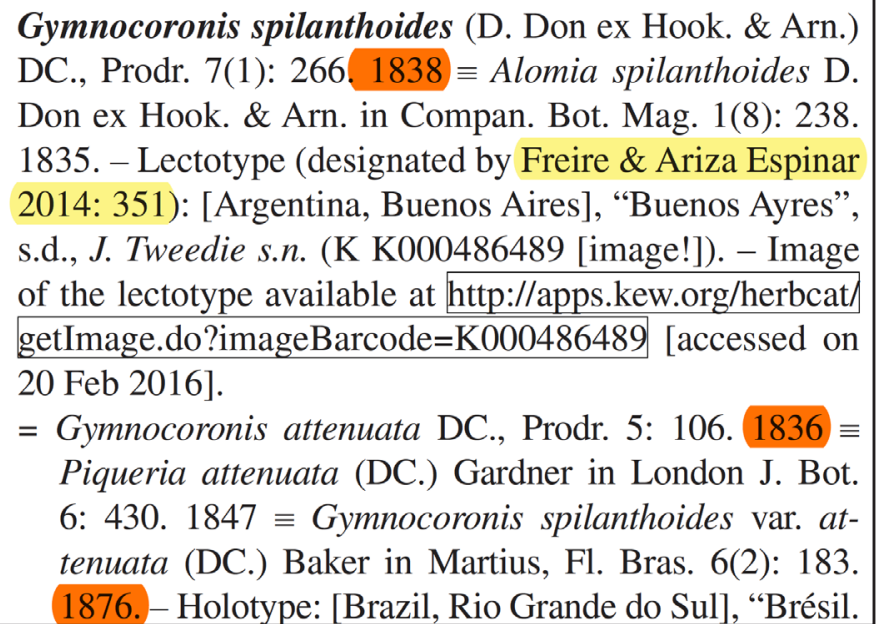 \\
\hline
\end{tabular}

Fig. 4. The references highlighted in orange are not listed in the References section whereas the reference in yellow, because it is recent, is listed (Ardenghi et al. 2016).

\section{Diagnosis}

This species is similar to Promalactis roesleri Lvovksy, 2000a, in the wing pattern, but it can be easily distinguished by the male genitalia with the valva blunt at apex, the juxta with a large hook-shaped lobe, and the aedeagus bearing distinctly developed two cornuti.

Leptocerus xanthographus Germar 1824, p. 424. Type material: from Buenos Aires, Argentina, probably in Halle, Germany (not seen).

Naupactus xanthographus: Schoenherr 1833, p. 571; Schoenherr 1840, p. 7; von Dalla Torre et al. 1936, p. 24 (catalogue); Blackwelder 1947, p. 795 (checklist); Hustache 1947, p. 39 (in key); Wibmer and O'Brien 1986, p. 62 (checklist).

Fig. 5. Authorship formally presented as a reference. A. Kim et al. (2017). B. Lanteri \& del Rio (2017). 
In a recent article published in Journal of Natural History (Fig. 5a), the way the author cites the species implies that a bibliographic citation is made. If the author and date were only part of the taxon name, as it is usually the case, it would have been "Promalactis roesleri Lvovsky, 2000" not "Promalactis roesleri Lvovsky, 2000a" which clearly refers to a bibliographic reference.

In palaeontology, the practice depends on whether the journal deals with palaeozoology or palaeobotany. One out of the five journals selected in palaeontology, the Journal of Paleontology, is very precise and instructs its authors to provide all authorship and dates, with their corresponding entries, in the bibliographic references section. As far as this could be checked, the rule is followed in practice.

The journals of the Muséum national d'Histoire naturelle (MNHN) have similar instructions to authors whether the journal specializes in zoology (Zoosystema) or palaeontology (Geodiversitas). Consequently, the same rule applies to both journals (Fig. 6). By instructing the authors to formally give the original reference of the description of the taxon alongside the taxon author and date, they strongly imply that the citation should be listed under the references section. Fig. 6 illustrates the most common practice regarding authorship citation in zoological journals.

\begin{tabular}{|c|c|}
\hline Genus Gyrostrea Mirkamalov, 1963 & 6B Family CAPSALIDAE Baird, 1853 \\
\hline $\begin{array}{c}\text { Gyrostrea delettrei (Coquand, 1862) } \\
\text { (Fig. 4G-N) }\end{array}$ & Allobenedenia pseudomarginata (Bravo-Hollis, 1957) \\
\hline $\begin{array}{l}\text { Ostrea delettrei Coquand, 1862: 224, pl. 18, figs 1-7. — Fourtau } \\
\text { 1917: 34; pl. 1, figs 1-4. }\end{array}$ & $\begin{array}{l}\text { Trochopus pseudomarginatus Bravo-Hollis, 1957: } 205 . \\
\text { Benedenia convoluta Bravo-Hollis, 1953: } 142 .\end{array}$ \\
\hline $\begin{array}{l}\text { Exogyra delettrei-Pervinquière 1912: 186, pl. 12, figs 18, ?19. - } \\
\text { Trevisan 1937: } 74 \text {, pl. } 5 \text {, figs 5-10. }\end{array}$ & $\begin{array}{l}\text { Megalocotyloides pseudomarginatus - Bychowsky \& Nagibina 1967:525. } \\
\text { Allobenedenia pseudomarginata - Yang et al. 2004: } 227 .\end{array}$ \\
\hline
\end{tabular}

Fig. 6. Authorships formally presented as references, those in yellow are listed in the references section whereas those in orange are not considered as bibliographic references. A. Musavu Moussavou (2017). B. Mendoza-Garfias et al. (2017).

species. In 1799 Lamarck created the genus Turritella, and in 1822 he placed Turbo duplicatus Linnaeus in it as Turritella duplicata. In 1849 Reeve synonymised the three species of Linnaeus under T. duplicata, which has been followed by most modern authors (e.g., Garrard, 1972; but see Paul et al., 2013). In 1840, Gray had listed the generic name Zaria, but did not give a type species, and so as of that date the genus was a nomen nudum (Neave, 1940: 693). In 1847 (p. 155), however, Gray proposed Turbo duplicatus as the type species of Zaria making the genus available (Marwick, 1957: 164). (Bouchet \& Rocroi (2005) incorrectly give Gray (1842) as the author of the genus.) Several authors in the past have used Zaria as a subgenus of Turritella (e.g., Tryon, 1883; Baluk, 1975, 2006; Beets, 1986).

Beu (2010) and Allmon (1996) point out that the generic-level systematics of the turritellines are, at best, inconsistent and problematic and that only molecular phylog-

\section{SYSTEMATICS}

Family Turritellidae Lovén, 1847

Subfamily Turritellinae Lovén, 1847

Genus Turritella Lamarck, 1799

Type species: Turbo terebra Linnaeus, 1758. Recent, Indo-Pacific.

Turritella duplicata (Linnaeus, 1758)

1758 Turbo duplicatus Linnaeus: 766.

1758 Turbo acutangulus Linnaeus: 766.

1758 Turbo replicatus Linnaeus: 766.

1822 Turritella duplicata (Linnaeus) - Lamarck, 1822: 56.

1843 Turritella duplicata "Lamarck" - Deshayes \& Milne-Edwards, 1843: 251.

1847 Zaria duplicata (Linnaeus) - Gray, 1847: 155.

1849 Turritella duplicata (Linnaeus) - Reeve, 1849: 571, pl. 1, fig. 2.

Fig. 7. In this article the reference highlighted in orange indicates a reference that is only cited under taxonomic treatment and listed under the references section; in yellow a reference that is cited elsewhere thus listed under the references section; in blue are the references that should have been listed but are not in the references section (Waite R. \& Allmon W.D. 2016). 
The instructions to authors in Malacologia are so unclear that they lead to extreme confusion regarding authorship citation and the way they should, or not, be cited under the references section. The example taken from an article published in 2016 (Fig. 7) shows that some authorship strictly referring to the name of the taxon are listed under the references section, while some references that are clearly bibliographic references are not listed in the references section.

\title{
Group 2: Taxon authorship cited but not referenced in the bibliographic section
}

Only one journal (Table 2) out of the 25 selected states explicitly in its instructions for authors that the authorship should not be listed in the reference section. Despite the clarity of the instructions, the first example we consulted in this journal showed that all authorship citations were listed in the references (Fig. 8). The article cited in Fig. 8 deals with palaeobotany but other articles in palaeozoology in this journal had a similar pattern.

Even if Geobios is the only selected journal to formally state in its instructions for authors that taxon authorship should not be listed as a reference under the bibliographic references, in practice several journals belonging to Group 3 (i.e., with no further precision on how to cite authorship and list their references) do not give full references for taxon authorships under the bibliographic section. These journals were nonetheless listed under Group 3 as they do not state this practice as an explicit rule.

\begin{tabular}{|c|c|c|c|}
\hline Field & $\begin{array}{l}\text { Journal } \\
\text { title }\end{array}$ & Publisher & Extracts from instructions for authors \\
\hline Palaeontology & Geobios & Elsevier & $\begin{array}{l}\text { Lists of synonymies should follow the example below (up to } \sim 15 \text { refer- } \\
\text { ences, lengthy lists should be provided as supplementary material): } 1921 \text {. } \\
\text { Andriopora limax nov. sp. - Lang, p. } 97 \text {, pl. 3, fig. 3. 1974. Ataxioceras } \\
\text { desmoides Wegele - Shairer, p. } 73 \text {, pl. } 9 \text {, fig. } 8 \text {. The bibliography should } \\
\text { not exceed } ~ 150 \text { references. References associated with Systematic Pal- } \\
\text { aeontology (taxon author's names and lists of synonymy) should not } \\
\text { be listed; nevertheless, they can be provided as Supplementary Material } \\
\text { if necessary. }\end{array}$ \\
\hline
\end{tabular}

Table 2. Samples of journals studied with extracts of their instructions for authors concerning authorship citation. Group 2: Cited but not referenced.

\section{Systematic paleobotany}

\author{
Division Pteridophyta Schimp. in K.A. Zittel, 1879-1890 \\ Class Equisetopsida C. Agardh, 1825 \\ Order Equisetales de Candolle. ex von Berchtold and Presl, 1820 \\ Family Esuidetaceae Michx. ex de Candolle, 1804 \\ Genus Equisetum von Linnaeus, 1753 \\ Subgenus ?Equisetum von Linnaeus, 1753 \\ Type species: Equisetum fluviatile von Linnaeus, 1753 (extant).
}

Fig. 8. All authorships cited highlighted in yellow are listed in the references section even though they are not cited as a bibliographic reference anywhere else in the text (Pole \& McLoughlin 2017). 
Group 3: No specific mention regarding taxon authorship citation appears in the instructions for authors

The majority of the selected journals belong to the third group identified (Table 3) as they do not mention any specific rules in their guidelines to authors regarding taxonomic authorship citation. However, in practice they differ. Some of them actually follow the same rule as in Group 1 but others are not consistent enough from one article to another to reveal a pattern, indicating some confusion over how citations are to be treated and included in the bibliographic references.

The botanical journals (such as Candollea, Adansonia, Cryptogamie Bryologie) in this group actually credit all the authors of the species (see example Fig. 9), including those in the synonymy list, providing extensive references with page numbers. However, those references are not repeated in the bibliographic section. Since the bibliometric tools relate exclusively to the references listed in the bibliographic section, these taxonomic references are not considered as formal citations and thus do not count as valid bibliographic citations for the journal impact factor, nor for the individual h-index of the researchers.

In the example taken from Zootaxa (Fig. 10), the author cites "Utinomi (1958)" in the synonymy list followed by the page number (the reference is cited nowhere else in the article) and thus this reference is included in the bibliography. This is the most common practice in zoological journals, whereby all citations must be listed in the references section and must be formally cited as a reference in the article. This rule is followed by Acta Chiropterologica, Zootaxa (however the rules followed in Zootaxa depend hugely on the group studied, as they are not consistent from one editor to another), ZooKeys, and is similar to the rule stated by the zoological journals of Group 1.

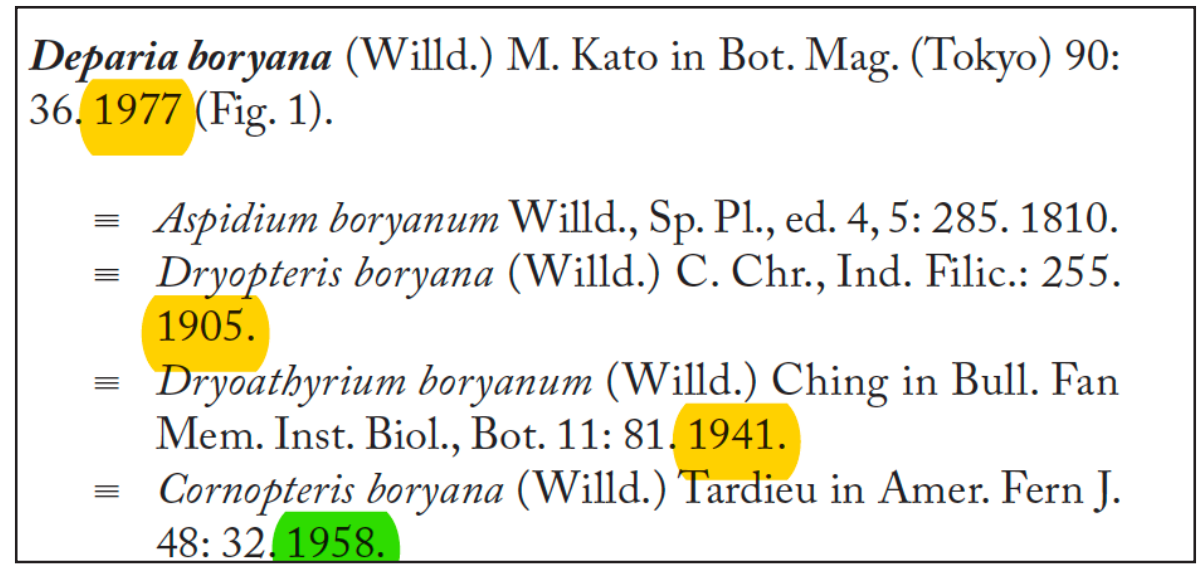

Fig. 9. In this example the references in yellow are not provided in the bibliographic section, but the the one in green is, because it has been formally mentioned elsewhere in the article as a reference (Rakotondrainibe \& Jouy 2016).

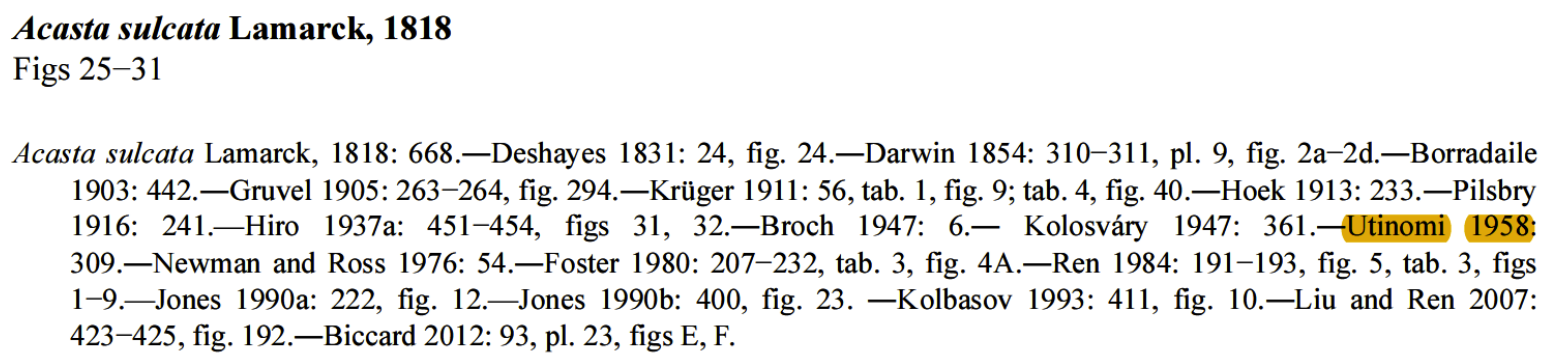

Fig. 10. In this article "Utinomi 1958" is cited only in the taxonomic treatment (but nowhere else in the text) and referenced in the bibliographic section (Yu et al. 2017). 
BÉNICHOU L. et al., Best practices in electronic publishing in taxonomy

This usual practice may, however, lead to some confusion in the HTML versions of the articles in which the authorship citations are linked in blue even when they are not considered as a reference by the author of the article (Fig. 11).

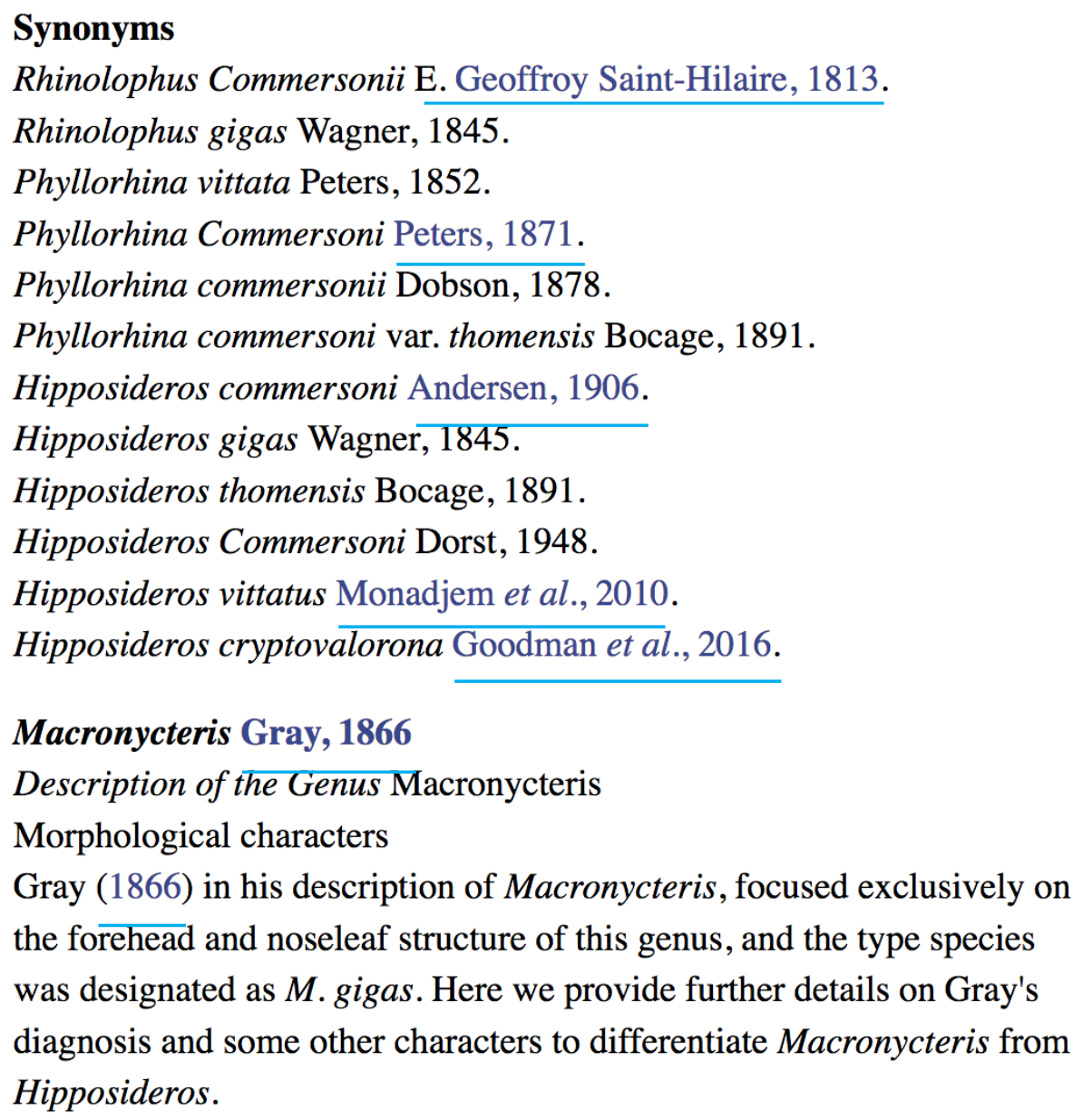

Fig. 11. Underlined in blue are the references linked to the bibliography (considered as such because they are cited in an unambiguous way elsewhere in the text) whereas those in black are not linked because they are not listed in the bibliography (Foley et al. 2017).

Epinephelus kupangensis, new species
urn:Isid:zoobank.org:act:792BAAE2-5FC0-4CBF-A41A-
0C4C8D97A1BA
Common Names: English-Fivebar grouper, Bahasa Indonesia-
Kerapu Bendera
Figure 1, Table 1
Epinephelus amblycephalus (Bleeker, 1857)

Fig. 12. Here "Bleeker, 1857" is considered by the authors as a bibliographical reference and listed as such under the references section although it has not been cited elsewhere in the text (Tucker et al. 2016). 
Table 3 (continued on next page). Samples of journals studied with extracts of their instructions for authors concerning taxon authorship citation. Group 3: nothing specific mentioned.

\begin{tabular}{|c|c|c|c|}
\hline Field & Journal title & Publisher & Extracts from instructions for authors \\
\hline Botany & $\begin{array}{l}\text { Cryptogamie, } \\
\text { Algologie/ } \\
\text { Mycologie/ } \\
\text { Bryologie }\end{array}$ & $\begin{array}{l}\text { ADAC } \\
\text { (LS hosted } \\
\text { MNHN) }\end{array}$ & Nothing in particular mentioned. \\
\hline Botany & Candollea & $\begin{array}{l}\text { Conservatoire et } \\
\text { Jardin Botanique } \\
\text { de la Ville de } \\
\text { Genève }\end{array}$ & Nothing in particular mentioned. \\
\hline Botany & Adansonia & MNHN & $\begin{array}{l}\text { Each systematic description should be arranged } \\
\text { as follows: name of the taxon with its author's } \\
\text { abbreviation, every taxon cited in the text should } \\
\text { be followed, when first mentioned in the text, in the } \\
\text { résumé/abstract and in the captions of the figures, by } \\
\text { its authorship; Authors' names must be abbreviated } \\
\text { according to Authors of Plant Names (Brummitt \& } \\
\text { Powell 1992). Abbreviations of herbaria must follow } \\
\text { Index Herbariorum, ed. } 8 \text { (Holmgren, Holmgren \& } \\
\text { Barnett 1990). }\end{array}$ \\
\hline Botany & Persoonia & $\begin{array}{l}\text { Naturalis } \\
\text { Biodiversity } \\
\text { Center }\end{array}$ & $\begin{array}{l}\text { Authorities of fungal taxa should be omitted from } \\
\text { the general text, unless novelties and synonymies are } \\
\text { listed, or nomenclatural issues discussed. In these } \\
\text { cases, authorities for taxa should follow the list of } \\
\text { authors' names, see http://www.speciesfungorum.org/ } \\
\text { AuthorsOfFungalNames.htm. Journal abbreviations } \\
\text { in the text (species synonymies, descriptions, etc.) } \\
\text { should follow the International Plant Name Index } \\
\text { (see http://www.ipni.org/index.html). No further } \\
\text { information is given concerning whether the reference } \\
\text { should be listed in the reference section or not. }\end{array}$ \\
\hline Botany & Taxon & $\begin{array}{l}\text { International } \\
\text { Association for } \\
\text { Plant Taxonomy }\end{array}$ & $\begin{array}{l}\text { Verify that all citations in the text are also in the } \\
\text { Literature Cited and vice versa. No further precision } \\
\text { is given concerning taxonomic authorship or their } \\
\text { inclusion in the reference section. }\end{array}$ \\
\hline Zoology & $\begin{array}{l}\text { Acta } \\
\text { Chiropterologica }\end{array}$ & $\begin{array}{l}\text { Museum and } \\
\text { Institute of } \\
\text { Zoology, Polish } \\
\text { Academy of } \\
\text { Sciences }\end{array}$ & Nothing in particular mentioned. \\
\hline Zoology & Copeia & $\begin{array}{l}\text { American society } \\
\text { of Ichthyologists } \\
\text { and } \\
\text { Herpetologists }\end{array}$ & Nothing in particular mentioned. \\
\hline Zoology & Zootaxa & Magnolia Press & Nothing in particular mentioned. \\
\hline
\end{tabular}


Table 3 (continued).

\begin{tabular}{|c|c|c|c|}
\hline Field & Journal title & Publisher & Extracts from instructions for authors \\
\hline Zoology & Zookeys & Pensoft & $\begin{array}{l}\text { Before submitting the manuscript, please check each } \\
\text { citation in the text against the References and vice- } \\
\text { versa to ensure that thev match exactly. } \\
\text { No further precision concerning taxonomic authorship } \\
\text { or inclusion in the bibliography is given. }\end{array}$ \\
\hline Zoology & $\begin{array}{l}\text { Annales de } \\
\text { la société } \\
\text { entomologique de } \\
\text { France }\end{array}$ & $\begin{array}{l}\text { Taylor and } \\
\text { Francis }\end{array}$ & $\begin{array}{l}\text { The author name and description date must be given } \\
\text { for each taxon at its first mention. Nothing in particular } \\
\text { is mentioned concerning inclusion of authorship } \\
\text { references in the bibliography. }\end{array}$ \\
\hline Zoology & $\begin{array}{l}\text { Zoological Journal } \\
\text { of the Linnean } \\
\text { Society }\end{array}$ & $\begin{array}{l}\text { Wiley and } \\
\text { Blackwell }\end{array}$ & $\begin{array}{l}\text { Cite the author of species on first mention. In the text, } \\
\text { give references in the following forms: 'Stork (1988) } \\
\text { said', 'Stork (1988: 331)' where it is desired to refer } \\
\text { to a specific page, and '(Rapport, 1983)' where giving } \\
\text { reference simply as authority for a statement. Note } \\
\text { that names of joint authors are connected by '\&' in the } \\
\text { text. When papers are by three authors, use all names } \\
\text { on the first mention and thereafter abbreviate to the } \\
\text { first name et al. For papers by four or more authors, } \\
\text { use et al. throughout. The list of references must } \\
\text { include all publications cited in the text and only } \\
\text { these. }\end{array}$ \\
\hline \multirow{4}{*}{ Palaeontology } & \multirow{4}{*}{$\begin{array}{l}\text { Palaeontographica } \\
\text { A/ Paleozoology } \\
\text { B/ Paleobotany }\end{array}$} & \multirow{4}{*}{$\begin{array}{l}\text { E. Schweizer- } \\
\text { bart'scher Verlag }\end{array}$} & $\begin{array}{l}\text { A/ In synonymy lists, species names and literature } \\
\text { references are separated by a dash in cases where the } \\
\text { describer is not the original describer of the species... } \\
\text { All publications referred to in the text of the paper must } \\
\text { be included in the reference list. Nothing particular is } \\
\text { mentioned about taxonomic authorship or inclusion in } \\
\text { the bibliography. }\end{array}$ \\
\hline & & & $\begin{array}{l}\text { B/ Each taxon name must be accompanied by the } \\
\text { author(s) name(s) and year of publication when } \\
\text { introduced for the first time in the text.In synonymy } \\
\text { lists, species names and literature references are } \\
\text { separated by a dash in cases where the describer is not } \\
\text { the original describer of the species. }\end{array}$ \\
\hline & & & $\begin{array}{l}1821 \text { Annularia spinulosa STERNBERG, vol. I, 2: p. } \\
\text { 32, pl. 19, fig. } 4 \text {. }\end{array}$ \\
\hline & & & $\begin{array}{l}\text { No further specification is given as to whether the } \\
\text { references should be listed under the reference section } \\
\text { or not. The journal is not accessible online so we could } \\
\text { not check their practices. }\end{array}$ \\
\hline \multirow[t]{2}{*}{ Palaeontology } & \multirow{2}{*}{$\begin{array}{l}\text { Comptes } \\
\text { rendus Palevol }\end{array}$} & \multirow[t]{2}{*}{ Elsevier } & $\begin{array}{l}\text { Please ensure that every reference cited in the text } \\
\text { is also present in the reference list (and vice versa). } \\
\text { Any references cited in the abstract must be given in } \\
\text { full. }\end{array}$ \\
\hline & & & $\begin{array}{l}\text { Nothing in particular is mentioned concerning } \\
\text { taxonomic authorship references or inclusion in the } \\
\text { bibliography. }\end{array}$ \\
\hline
\end{tabular}


Contrary to the other journals selected from Group 3, Copeia does not comply with this rule. Indeed, as far as we could judge from checking random articles published in the journal, taxon authorship is always given a full entry in the bibliography, either when it is unambiguously cited as a reference (by adding the page numbers for instance), or even when it is simply cited after the name of the taxon without any other indication (see Fig. 12).

The same contradiction between the instructions and publishing practices was seen in articles in the Zoological Journal of the Linnean Society. Even though its instructions indicate that "the list of references must include all publications cited in the text and only these", we found examples in which all authorships were listed in the references even if they were not formally cited as such in the text (see Fig. 13).

Some rapid conclusions can be drawn from this study regarding common authorship citation and bibliographic references in taxonomic journals:

A. Most zoological journals have a common practice: the authorship follows the taxon name and is not considered as a reference per se. It is listed in the bibliographic references only if it is cited formally (either by indicating the page numbers after the date or by using a sentence such as "Smith (1958) described the species...").

B. The general practice with regard to authorship in botany papers is to mention the author of the description, without the date. In the synonymy list given for a specific taxon, the bibliographic references are usually listed. However, two rules predominate and depend on the journals: either the references cited in the synonymy list under the taxon name are repeated in the bibliographic section or they are not (see example in Fig. 9). In this latter case, they are not counted as references that are taken into account by bibliometric tools that relate exclusively the references listed under the bibliographic references section. Thus, in this approach, the citations of the references are reduced.

The main issue raised is clearly the need to define what constitutes a bibliographic reference and what constitutes the taxon name.

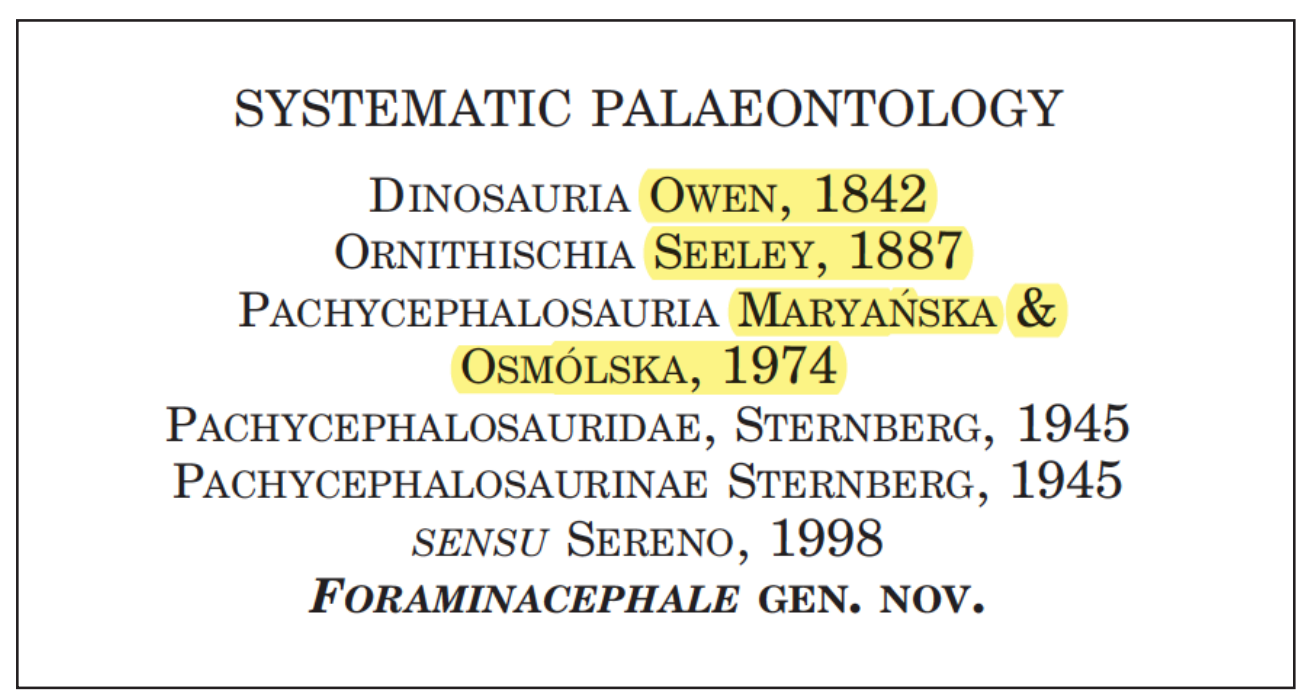

Fig. 13. The authorships highlighted in yellow are cited nowhere else in the article and yet they are listed in the references section (Schott \& Evans 2016). 
BÉNICHOU L. et al., Best practices in electronic publishing in taxonomy

Before making any recommendations to taxonomic journals on how best to address the issue raised, the discussion at the workshop aimed to understand what was really at stake with respect to authorship citation.

\section{Discussion regarding authorship citation}

\section{What is really at stake in improving citation of taxonomic description authorship in scientific papers?}

The first issue identified has to do with scientific accurateness. Proper citation of taxonomic authorship accurately indicates which species is actually meant in the publication, avoiding ambiguity and errors, and assuring that the scientific name being used is both valid and understood.

Discoverability is the second issue that has been raised. Common elements that appear in taxonomic papers, generally considered as a citation, are sometimes not sufficient to properly identify the author, and thus to find the original publication in which the scientific name was first proposed.

The last point is related to the evaluation of researchers. Indeed, as was underlined by Seifert et al. (2008), citation of the original publication raises an author's citation record and can increase the Journal Impact Factor. According to Bouchet et al. (2016), "78\% of the new species [of molluscs] are described in journals/books without an ISI impact factor". However, there are more bibliometric indices available than just the Journal Impact Factor (JIF) of the Web of Science. Google Scholar counts many more citations than those retained by Web of Science, and individual researcher profiles in Google Scholar are increasingly used for individual assessments, in parallel with JIF data.

An argument against the formal citation of the authors of names and the original descriptions of taxa is the fact that the JIF is calculated over a period of two or five years, meaning that most citations are therefore omitted in the 'slower' field of taxonomy. In addition to the five-year impact factor now provided by Clarivate Analytics, other metrics, for example those of Google Scholar, Scopus (SCImago Journal Rank), Eigenfactor (AI) and others, have a cumulative index that considers all citations over time, which could start to resolve this imbalance and ensure that 'historical' citations also continue to count. An additional important point regarding all the metrics cited should be emphasized: Google Scholar, SJR and AI are free whereas JIF and Scopus must be paid for (Thomaz \& Martens 2009).

The workshop concluded that scientific accurateness and the need for discoverability are the most important issues in improving taxonomic authorship citation, with researcher evaluation by impact factors (or equivalent) metrics coming third to these other issues. Improving authorship citation of taxonomic names can have a positive effect on other bibliometric indices, which are also increasingly used, so crafting guidelines on how to cite taxon authors could be potentially useful to the taxonomic community.

\section{Which best practices and tools could be adopted or developed to improve authorship citation?}

In taxonomic papers the basionym, the typification and other elements allowing the reader to identify and find the original description must be cited (author, date, journal title) when a scientific name is included in the taxonomic treatment part of a study. Taxon authorship citation is thus used a lot in an article of this type. But there are other sorts of citation that taxonomists could have: author of a nomenclatural novelty (e.g., a recombination in botany); authorship of a treatment or a typification; authorship of taxonomic concepts and related concepts of synonymy.

Should taxonomic treatments refer, at least, to the original descriptions, and if so, should these be cited in the reference section? If the original description paper was cited in the bibliographic reference section this would make it easier to find. A good practice would be to cite the original description in the 
bibliographic references when it is considered relevant for the reader to be able to refer to it directly. Furthermore, bibliometric tools enable citations to be crosslinked and help readers to browse and move from one article to another. This type of electronic access to literature is not possible if a reference to an authorship in the article is not considered as such in the reference section.

During the discussion within the workshop, some participants argued that tools should be provided to taxonomists to cite the authors of scientific names correctly, fully and in a user-friendly way. Such tools would improve discoverability of the original publication, even when it is not cited in the article. They could also make researchers change their habits and more easily apply best practices for authorship citation.

Improving discoverability of original publications of scientific names, as much as that of the visibility of taxonomic authorship, can be done by developing unique identifiers for each author. With the increase of e-publications and the issues that arose around homonyms, some different systems have been developed, such as Orcid ID (a unique identifier for scientific and other academic authors and contributors which is increasingly used in universities), or the VIAF authority (Virtual International Authority File) database which works following a similar system of unique identifiers for authors (however, VIAF is more orientated towards books than to journals), but which seems more accurate as it is made by using author files from national libraries. ZooBank accommodates the registration of three different kinds of data objects for which a Life Science Identifier (LSID) is attributed: nomenclatural acts, publications and authors. ZooBank is the Official Register of the International Commission on Zoological Nomenclature (ICZN) that provides the central, authoritative and comprehensive resource for scientific names in zoology. Registration of e-only nomenclatorial acts using ZooBank LSID's is compulsory (see above).

It seems appropriate that large taxonomic databases like Catalogue of Life $(\mathrm{CoL})$ clearly identify the associated original descriptions in their list of synonyms, with a link to the full publication reference. Relevant data aggregation databases like the Global Biodiversity Information Facility (GBIF) should also provide the full reference, ready-for-use by the authors. As the largest reservoir of publications used by scientists from all disciplines related to biodiversity, the Biodiversity Heritage Library (BHL) has a key role to play in addressing and resolving this matter, with the support and collaboration of the whole community.

While discussing the development of international tools based on data exchanges, the workshop underlined that it is important to ensure that all parties correctly cite a proper license such as Creative Commons by attribution (CC-BY), which facilitates data aggregation and re-use. Furthermore, easy standardized ways of citing must be provided, along with controlled vocabularies, so that automated citation can be implemented when names are used from large aggregators like GBIF. It is crucial to enable interoperability by matching data fields from one system to another.

\section{What are the most common metrics used to evaluate taxonomic research and researchers?}

If the adoption of better practices in citing taxonomic authorship does not have a significant impact on the metrics that are mostly frequently used (Journal Impact Factor, the h-index), it seemed relevant to raise the topic of which alternative metrics would be needed to evaluate both taxonomic research and taxonomy researchers more equitably and effectively.

Apart from activities that lead to the publication of scientific papers and their resulting citations (summarized in a range of impact factors and indices), other criteria may also be used to evaluate taxonomic research and taxonomy researchers. Some of them, more appropriate to taxonomy, have already been suggested (Valdecasas 2011, 2014; Páll-Gergely 2014). Each university and research institute will apply its own set of evaluation criteria, but many of these are recurrent, such as teaching 
BÉNICHOU L. et al., Best practices in electronic publishing in taxonomy

courses, guiding students, conducting service-related research, editorial and reviewing activities, etc. Increasing the number of authorship citations of taxonomic names may thus have a limited impact on the totality of data used for evaluation and resulting recruitment or promotion. It would, however, improve the ease of tracking biodiversity literature while increasing its visibility and accessibility, all by means of a reasonably small effort.

Metrics applied to physical collections of an institution could also be considered, based on tracking specimen citations via the use of the unique identifiers attributed to specimens that are also cited in publications. Collections, institutions and their staff need to be cited so that the metrics can be applied properly. This is the collective challenge that institutions, as well as individuals, must now tackle.

Proposing alternative metrics that are more pertinent to taxonomy will not be effective unless a majority of data that have already been published, as well as those that are published from this point on in scientific journals, are accessible with no technical or legal barriers. Full Open Access is thus a prerequisite for achieving this goal.

\section{E-publishing and Open Access (OA)}

Before delving into recommendations for e-publishing, a review of some common characteristics of scientific journals is provided below.

\section{E-publishing}

\section{Economic models for scientific journals}

The market for academic journals is different from the standard publishing market as neither the author(s) nor, in general, the editors or reviewers are paid for their expert involvement with publishing an article. Reviewing and editorial work is given as an in-kind service to the scientific community, a type of reciprocal altruism, with the tacit agreement of the employing institutions. Different economic models for scientific publishing exist (Fig. 14).

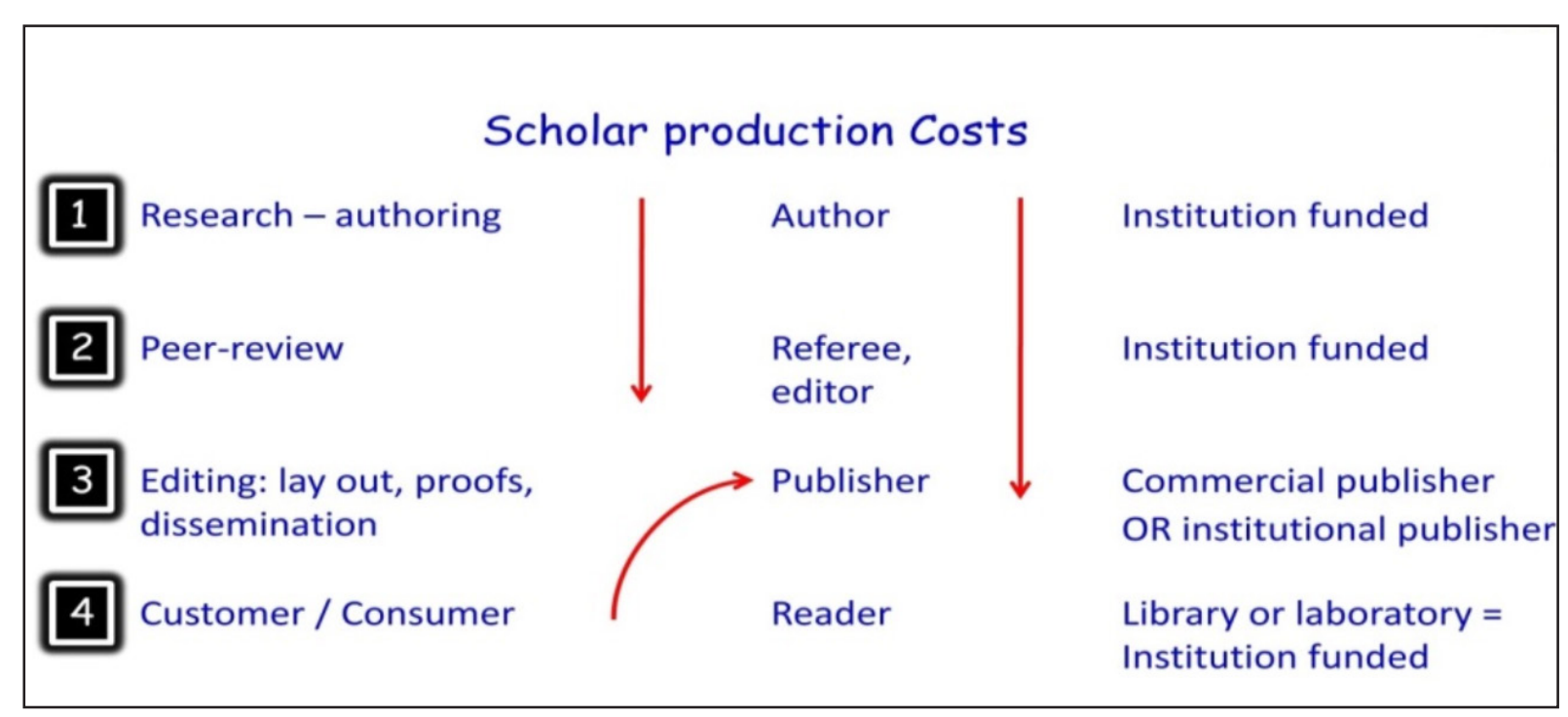

Fig. 14. Scholar production costs. Four steps are needed to produce scholar papers, of which three are publicly-funded. In the first scenario, the library pays back the final product by subscription to the publisher while in the second, the publishing costs are supported by the publisher (commercial or institutional) and then the access is free for the reader. 
Reader pays model (subscription or pay-per-view). Readers or libraries pay subscriptions or consultation fees to read a paper/journal. This model used to be applied in traditional scientific publishing. It implies that institutions frequently have to pay to read their own research results. In taxonomy, since the $19^{\text {th }}$ century, the traditional way for disseminating research results has been through the exchange of institutional journals between publishing institutions. Subscriptions to commercial publishers, however, seriously impact the budget of the libraries themselves.

Author pays model. Authors, or more commonly their institutions, have to pay a fee for an article to be published directly online, with free access for readers. These fees are also known as 'Article Processing Charges' (APC). This model implies that institutions have to pay a third party, from public funds, for the dissemination of their own research results (that are also often supported by these same public funds) to the scientific community.

Full Open-Access model (institution pays model). Neither the author nor the reader has to pay, but instead institutions and/or public funders cover the production costs of the papers and journals (see below 'Diamond Open Access').

Hybrid (mixed) models. In this case, both the traditional paper version and immediate digital access is provided by the journal, usually for a high APC. A problem with this model is that journals may practice so called 'double dipping' (see explanation below).

\section{Online or E-publishing}

Journals are increasingly available online, although digital dissemination on a website or platform does not necessarily comply with OA standards (see below).

The digital support associated with OA also gives the opportunity for researchers to enrich a publication with three categories of information: research data; supplementary materials (to illustrate or clarify issues); and post-publication data (commentaries, rankings). Journals can now publish their papers in HTML or XML formats, which offer the option to link articles to maps, databanks, multimedia files, and so on.

Another important advantage of OA is that it allows for automatic harvesting by search engines, enabling superior visibility and more citations for the research findings.

E-publishing also offers the possibility to implement a fast-track publishing process, which means a shorter timeline between submission and publication. Such an accelerated submission, selection and peer-review system can allow articles to be published online in a few weeks or even days. Of course, this must be achieved with scientific quality control (peer review) and for taxonomic papers, compliance with the relevant nomenclatural codes.

\section{Bibliometrics and the impact factor}

With (free) online access to scientific articles, journals become better known and can become more frequently cited (Swan 2006; Wang et al. 2015; see also the OpCit. Project 2013). Metrics thus become more and more important for journals themselves.

For publicly-funded research, resulting publications should be considered as an essential part of the research process. Evaluating them is a fundamental process that is used for assessing scientific results and research projects as well as researchers and/or research teams, because they play an essential role in determining the 'value' or 'success' of the research performed.

Bibliometrics refer to a set of methods used in assessing research performance by counting the number of publications, the impact of the scientific journals in which they appear (the potential readership for 
BÉNICHOU L. et al., Best practices in electronic publishing in taxonomy

the articles) and the number of publications that cite them, in a given time period. These methods seem simple because they are based on simple counting and their application can be automated.

Metrics show that digital and, in particular, OA papers obtain more citations faster than printed ones (Gargouri et al. 2010; see also the OpCit. project 2013). Due to their autonomous nature, they may also be perceived as more objective. However, these metrics may be completely off-target for use in a qualitative evaluation.

The most frequently used bibliometric statistics are the following:

- the number of papers published by a researcher or research group in a given period, as an indication of productivity;

- the frequency with which a published paper is cited in later publications by other researchers, as an indication of the interest this paper has raised;

- the frequency with which an electronically available paper is downloaded by readers, as an indication of its importance; or, to word differently the latter two metrics: download shows interest, citation shows importance;

- the average frequency with which papers in a given journal are cited during a given time span after publication, is supposed to be an indication of the scientific quality of the journal or of the thoroughness of its peer review (European Commission 2017).

Clarivate Analytics manages a large database (created by the ISI-Institute for Scientific Information, previously run by Thomson Reuters) covering 11,655 journals from over 2,500 publishers (Journal Citation Reports) (Johnson et al. 2018) and more than 700 million cited references. It contains the following information:

- the total number of articles published in the journal during the years considered;

- the total number of citations of each journal during the years considered;

- the main 2-year impact factor per journal;

- the 5-year impact factor: the same as above, but for 5 years instead of 2 (this is important for subject fields that evolve more slowly, although it may still be too short for taxonomy);

- the immediacy index: average number of times an article is cited in the year it is published calculated by dividing the number of citations to articles published in a given year by the number of articles published in that year;

- journal cited half-life: refers to the median age of the citations received by the journal during the considered year. If a journal has a Cited Half-Life of 4 , it means the median age of citations is 4 years half of the citations are to items newer than 4 years, and the other half are older.

The Journal Impact Factor is one of several statistics for impact at a journal level: it quantifies the average number of citations of an article in a journal within the two years following its publication. This equates to the number of citations during the current year of articles that appeared in this journal during the two previous years, divided by the number of articles that appeared in this journal during these two years.

\section{Open Access (OA) approaches}

Open Science encompasses various applications, which are all rooted in the 'Open' philosophy and benefit from open technology. Open Science is advocated by people who believe in the importance of a transparent and shared scientific endeavour and full access to research results as well as the underpinning data. Open Science, Open Research, Open Data, Open Education etc. have now become mainstream terminology. 
OA relates to scientific or academic publications, produced with taxpayer's money, and to their underpinning data, as a means to wider knowledge dissemination and reproducibility.

The CETAF workshop was more specifically focused on OA to publicly-funded peer-reviewed publications in zoology, botany and palaeontology, particularly in the field of taxonomy.

\section{Definitions}

OA has been defined through three public statements from the early 2000s (Budapest Open Access Initiative Declaration 2002; Bethesda Statement 2003; Berlin Declaration 2003).

OA is defined herein as: providing unrestricted and immediate access to electronic documents, giving users the right to free, irrevocable, and universal access.

OA to scientific publications thus means not only free access for any user but also includes the right to read, download, print, copy, distribute, search, crawl, mine and link to the full text for any purpose, with no reservations but with the (often ignored) attribution obligation (H2020 Programme).

It is important to stress that not every online publication on websites, blogs, social media or scientific networks like ResearchGate can be considered as OA. Certain conditions have to be met: platforms or repositories have to be Open Archiving Initiative-Protocol for Metadata Harvesting-OAI-MPH compatible; metadata have to be Dublin Core Standard and works have to be reusable without legal barriers, with licences such as CC-BY from Creative Commons (http://creativecommons.org/ licenses/by/3.0).

There are different approaches to OA. The main differentiation separates Green from Gold OA. Diamond OA is a subcategory of Gold OA. (Fig. 15).

Green Open Access or Self-archiving. This is the act of (the author) depositing a digital copy of, typically, peer-reviewed scientific articles or monographs, but also other types of research output, in an institutional or thematic repository, also called an 'open archive' (Suber 2012). In some institutions or universities this archiving is mandatory (see below).

Gold Open Access or Open Access Publishing. This refers to scholarly articles or monographs that are provided online by the publisher to the reader without financial, legal, or technical barriers (Budapest Open Access Initiative Declaration 2002). In Gold OA, an article is immediately published in OA mode. In this model, publication costs are no longer covered by the reader. One well-known business model is based on one-off payments by authors. These costs, commonly referred to as Article Processing Charges (APCs, see below), are usually borne by the researcher's university or research institute, or the national or international funding agency that supported the research (European Commission 2017). This APC based publisher provided model benefits from the 'Offsetting model', which promotes offsetting of subscription funds to funds earmarked for APC.

Diamond Open Access. This refers to scholarly articles or monographs provided online by the publisher to the reader without financial, legal, or technical barriers and no longer related to APC or subscription fees. This is in fact an improved version of Gold OA in which neither the author nor the reader has to pay! Costs are typically covered by a public institution, a consortium of public institutions or via subsidies. With this model, institutions retain control over their editorial and dissemination policies (the CETAF endorsed European Journal of Taxonomy is a Diamond OA publication). 


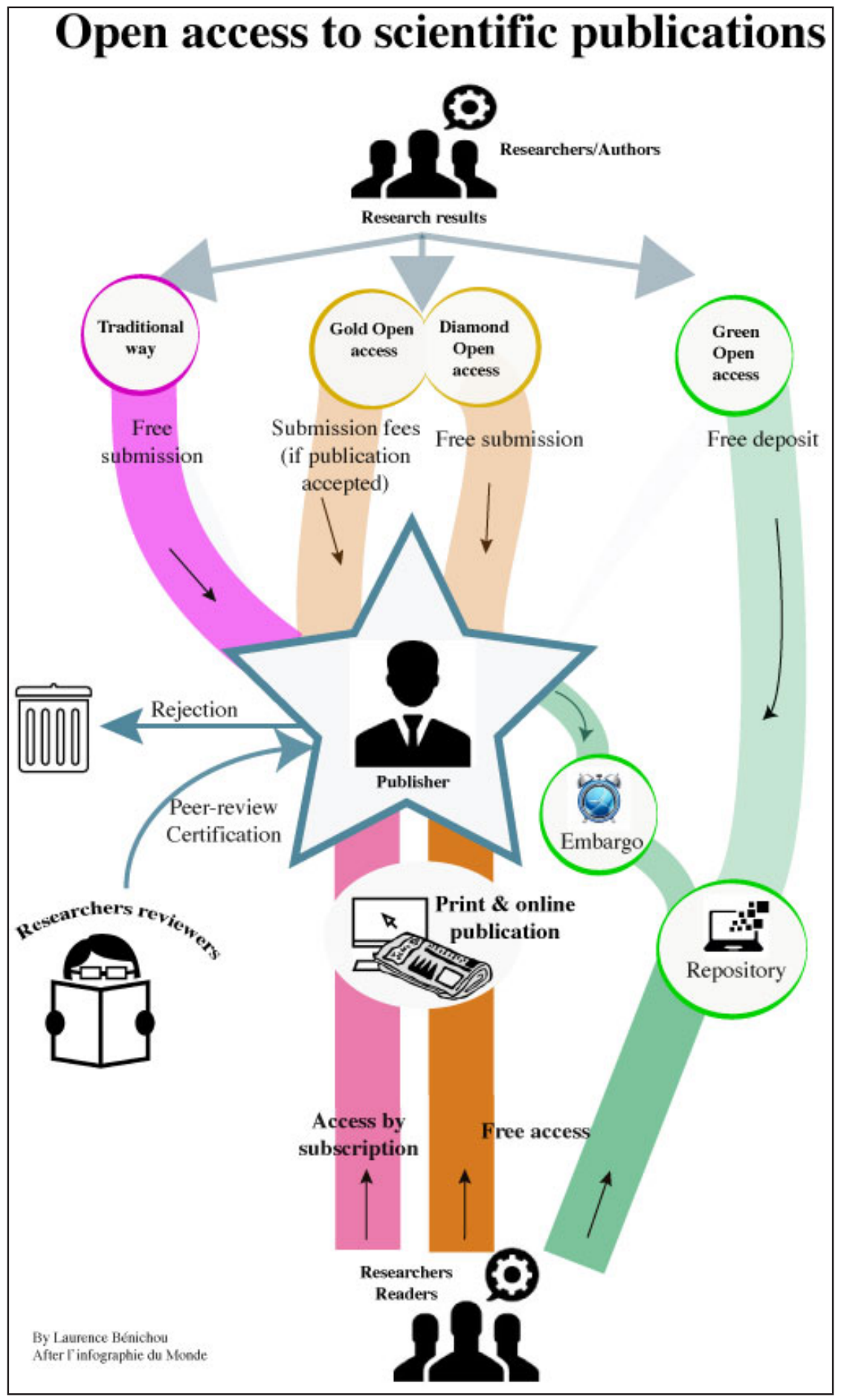

Fig. 15. Different routes for disseminating scientific publications (Cabut \& Larousserie 2013, redrawn by Laurence Bénichou from Infographie du Monde). 


\section{Open Access rules}

Many rules govern OA dissemination. Publishers, in particular major commercial outfits, impose different obligations because in the current online and digital world, scientists readily and willingly share results as soon as they are published.

Commercial Gold OA publishers require authors to abide by their policies, which are available on their websites, but they are also inventoried on the SHERPA-RoMEO portal (http://www.sherpa.ac.uk/romeo/index.php).

Pre-prints and post-prints. Publication of articles in peer-reviewed journals often take a long time because of long peer-review processes. Consequently, some journals authorise the distribution of preprints or post-prints. This indulgence is fuelled by a need to circulate research results rapidly within the scientific community which in turn leads to rapid peer feedback which can be helpful for revision and preparation of the final text, and lead to increased visibility for the publishers themselves.

- Pre-prints are manuscripts prior to peer review;

- Post-prints are peer-reviewed texts in production for publication.

Both are now also known as e-prints and may differ from the published final version (layout, revisions of content, updates, copyediting). In taxonomy (see Part 1: nomenclature rules), circulation of pre-print or post-print articles online is discouraged as this practice may invalidate nomenclatural acts.

Embargoes. These are delays imposed by publishers on OA for publications deposited in institutional (or thematic) repositories (Green OA). European Commission recommendations are to limit these embargoes to 6 months in scientific, technological, engineering and medical fields, and to 12 months in humanities, arts and social sciences (European Commission 2017).

Copyrights and licence. Whether publishing the traditional way or online, copyright holders no longer need to sign a formal agreement with the publisher but they nevertheless check-mark agreements or accept policies on the journal's website which do not authorize free dissemination.

If authors later wish or are required (mandatory in their institutions or due to funding rules) to archive their articles in a repository (Green OA), they have to retrieve rights that have already been ceded to the publisher. A licence or a simple authorisation per rider from the publisher, allowing for integration of their work in this repository and making its content public will do. Embargo periods or certain layout changes (or the use of a post-print) may be required.

For papers published directly in OA (APC based Gold or Diamond OA), an internationally recognized set of standard licences, known as Creative Commons (CC), have been developed to enable the sharing and use of knowledge through free legal tools without losing attribution. They are a simplification of existing copyright rules, adapted to the individual country's legislation. Before accessing the full text, if available, the user has to accept the terms of the Creative Commons licence.

\section{National policies and European mandates on OA}

Since the onset of OA, advocates have been busy promoting OA or even obliging OA for publicly funded research results, particularly for scientific papers. This implies strongly encouraged or mandatory deposition in a recognized OA repository.

One of the first funding agencies with a voluntary OA policy was the US National Institute of Health (NIH) in 2005. In 2007, the US Congress made it compulsory for NIH funded scientists to deposit their papers in the agency's archive within 12 months of publication. In 2017, the Registry of OA 
Repository Mandates and Policies (Roarmap) listed 769 funding organizations that had adopted an OA policy (Fig. 16).

Access to publications has been recommended repeatedly by international authorities and prestigious institutions, such as the Max Planck Society, which had over 600 institutions, agencies, governments and stakeholder associations sign the landmark Berlin Declaration (2003). Signatories included funders, policy makers, governments and research institutions as well as most CETAF members.

Starting July 2012, the European Commission fostered access to and preservation of scientific information:

- The European Commission issued a recommendation to make OA the main publishing tool for public funded research;

- The European Commission's Horizon 2020 programme made OA mandatory;

- All H2020 funded scientific publications must be deposited in the OpenAIRE Green OA repository with the aforementioned 6- to 12-month embargoes.

It is not compulsory but strongly encouraged to make underpinning research data publicly available online.

International organizations such as the European Commission and the Organisation for Economic Co-operation and Development (OECD) called for a swift implementation of OA through the creation of repositories, the development of compatible OA policies and the sharing of best practices internationally. Moreover, the Max Planck Society and the 2016 Dutch EU Presidency (Amsterdam Call for Action on Open Science, April 2016), followed by the so-called PlanS in 2018 (http://openaccess.ox.ac.uk/2018/10/10/plan-s-coalition-s-science-europe-oa/), called on European Union member states to achieve full OA by 2020, "offsetting" all subscription budgets to APC funds.

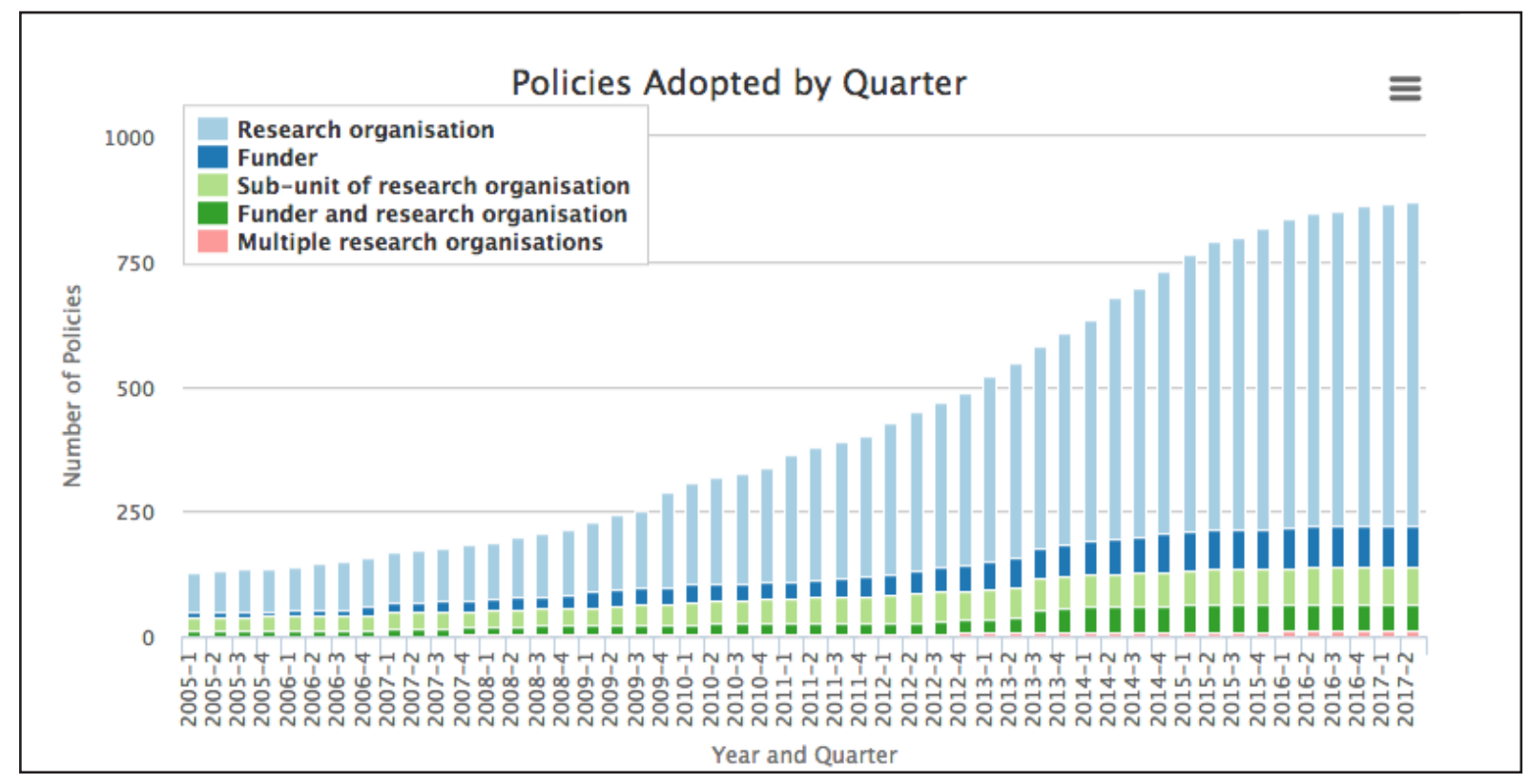

Fig. 16. Scheme extracted from Roarmap showing the different policies regarding Open Access. 
More specifically geared towards biodiversity studies, the Bouchout Declaration (2014) encourages some of the following Open Biodiversity Knowledge Management principles: providing infrastructure, standards and protocols; developing the right policies and licenses; and OA to digital resources about biodiversity. In 2016, the Jussieu call for Open Science and bibliodiversity promotes a scientific publishing Open-access model fostering bibliodiversity and innovation without involving the exclusive transfer of journal subscription funds to APC payments and clearly states that priority should be given to business models that do not involve any payments, neither for authors to have their texts published nor for readers to access them (Jussieu Call 2016).

\section{OA advantages}

See Fig 17.

\section{Open Access excesses}

OA is not just about dissemination, transparency and sharing. It has also been the principal tool used against what may be considered as excessive profiteering by some of the major publishers of scientific articles.

Facing the creation of multiple OA repositories worldwide, these commercial publishers have themselves adopted the OA principle by selling authors the possibility to publish online by means of APCs. This Gold OA model, which benefits from the offsetting model, is not welcomed by everyone (Earney 2017). Offsetting agreements explicitly link subscription and APCs, seeking to reduce one as the other grows.

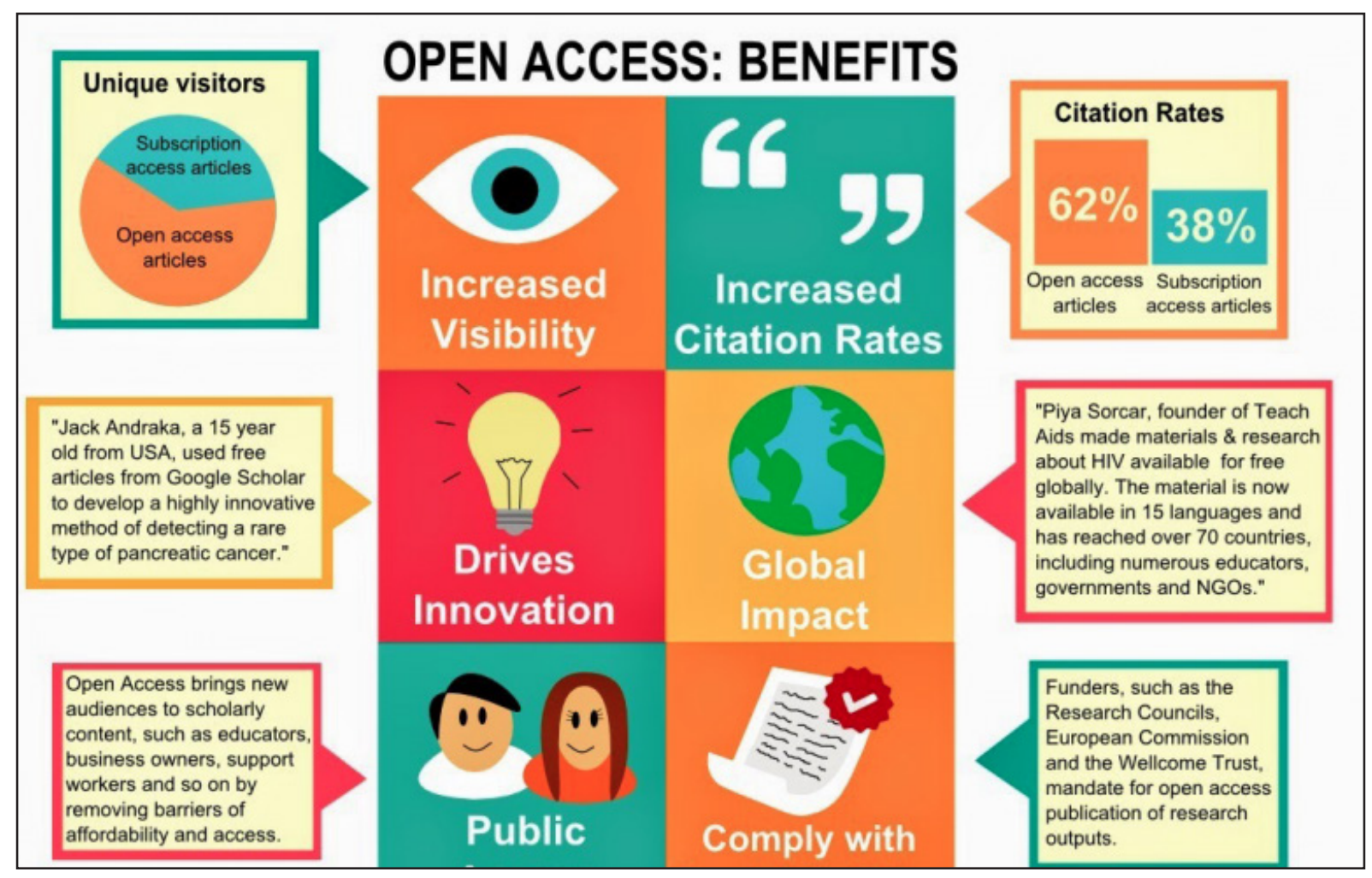

Fig. 17. Open Access benefits, from Aston University Library Services (available from https://www.yearofopen.org/march-open-perspective-open-access/). 
BÉNICHOU L. et al., Best practices in electronic publishing in taxonomy

Fears of overexaggerated APCs have prompted many public authorities to prefer the more laborious creation of institutional repositories where scholars or researchers are invited, or even obliged, to deposit their work for archiving and dissemination purposes. One of the major disadvantages of Green OA is the embargo, which delays actual access to the deposited material. One has to bear in mind, however, that such embargoes are not inherent to Green OA itself, but are imposed by commercial publishers.

Public authorities not only fear the replacement of excessive subscriptions by equally excessive APCs, but also the accumulation of both costs known as 'double dipping', a practice recently denounced by Carlos Moedas, the EU Commissioner for Research, Science and Innovation in 2015 (Moedas \& Dekker 2015). Member states such as Germany, France and Belgium have since passed 'Right to Secondary Publication' laws that allow authors to make articles available immediately in Green OA, no matter what their publisher contracts state.

\section{Different approaches to $\mathrm{OA}$}

All countries agree to a combination of Gold and Green OA, not least to allow for a greater degree of scholarly freedom but also simply because official publishing (for scholarly evaluation) happens through Gold OA. Green OA almost exclusively serves as an archiving tool. However there is a tendency for Eastern European countries, the Netherlands, Sweden, Austria and the United Kingdom, among others, to trust Gold OA (with APC) for superior dissemination, whereas France, the USA, China, Belgium, Switzerland and the Mediterranean countries favour dissemination through Green OA (institutional or independent thematic repositories).

The choice of the first group is based on Green OA disadvantages: repositories are slow to fill up; the process is complicated, resisted by researchers; there are copyright issues and embargoes that delay online dissemination, etc.

The second group fears that APC-based solutions will pave the way for the continued excessive publisher profiteering, mostly at the expense of public funds. It recommends strong archiving mandates, favours repository creation and legal protection from publisher supremacy.

\section{Recommendations and proposals of best practices related to authorship citation in E-publishing and OA adopted by CETAF}

As a conclusion, two sets of recommendations are presented herein that were adopted by the CETAF at its Governing Board meeting in London in April 2018.

On both topics, authorship citation and OA, a first set of recommendations focused on the taxonomic community's best interests are made to the institutions and stakeholders. A second group of recommendations are aimed at the taxonomic journals and their editorial boards and, finally, a third set of recommendations is proposed to scientists when acting as authors.

\section{Recommendations regarding Authorship citation}

\section{A) Recommendations from the institutional and/or community point of view}

The main issues to be addressed are:

What should we do as a community regarding authorship citation? Or to word it differently:

- should the name and date indicated after the species be considered as a reference and thus listed under the references section, or should it be somehow considered part of the taxon name to avoid ambiguity? - should all references, including when exclusively used in taxonomic treatments, be provided in the list of references? What should be considered a reference? 
How should we credit all authorship (if this is what the community thinks is desirable) and make sure an authority is cited as a bibliographic reference and listed under the references section?

\section{Recommendation 1. Recommendations regarding Authorship citation in Zoology and Palaeo- zoology}

1.1. Follow recommendation $51 \mathrm{~A}$ of the ICZN which states that "the original author and date of a name should be cited at least once in each work dealing with the taxon denoted by that name". Authorities: Author, date after the taxon name, e.g., Eviulisoma ejti Enghoff, 2018; Eviulisoma cetafi Enghoff, 2018

1.2. Authorship is only to be considered as a bibliographic reference if it is formally cited as a reference in the article, by indicating, for instance, the page number. In this case, it is mandatory to report the reference under the References section, e.g. (below), from EJT: the first line below refers to the taxon name (the title of the treatment) and is not a bibliographic reference, while the second line refers to the original publication in which the genus was described and is a bibliographic reference:

Genus Sylvicanthon Halffter \& Martínez, 1977

Sylvicanthon Halffter \& Martínez, 1977: 36, 45, 61-63.

Recommendation 2. Recommendations regarding authorship citation in Botany and Palaeobotany

2.1. Follow the recommendation of Art. 49.1 of the ICN stating that "when a genus or a taxon of lower rank is altered in rank but retains its name or the final epithet in its name, the author of that earlier name, if it is legitimate (i.e., if it is the basionym; Art. 6.10), is cited in parentheses, followed by the name of the author who effected the alteration (the author of the name). The same provision holds when a taxon of lower rank than genus is transferred to another genus or species, with or without alteration of rank." Authorities: Author after the taxon name, e.g., Begonia wattii C.B.Clarke.

2.2. Authorship is not to be considered as a bibliographic reference except if it is formally cited as a reference in the article, by indicating, for instance, the page number. In this case, it is mandatory to report the reference under the References section, e.g.:

\section{Begonia aborensis Dunn [sect. Sphenanthera]}

Bulletin of Miscellaneous Information, Kew 1920: 109.

2.3. When a bibliographic reference is indicated in the taxonomic treatment it has to be cited under the Reference section, e.g., below the original description is referred to under the taxon treatment entry and the bibliographic reference is mentioned between brackets to ensure the inclusion of this reference in the bibliography:

\section{Begonia aborensis Dunn [sect. Sphenanthera]}

Bulletin of Miscellaneous Information, Kew 1920: 109 (Dunn 1920).

Recommendation 2.3 is much more explicit and ensures that the reference will be listed in the bibliography. This approach, followed by the European Journal of Taxonomy when dealing with botany, is similar to that used in Zoology and is both human - and machine - readable. 
BÉNICHOU L. et al., Best practices in electronic publishing in taxonomy

B) Recommendations to journal editorial boards

Recommendation 3. Recommendations for journals published by or on behalf of CETAF members

3.1. Rules regarding authorship citation and their respective inclusion, or not, in the bibliographic references are to be clearly stated in the Instructions to Authors.

3.2. Consistency in the Rules enforcement is to be pursued.

\subsection{All references cited in the main text must be listed in the References section.}

3.4. The References section must include all publications cited in the text and only these.

\section{C) Recommendations to the authors}

Recommendation 4. General Recommendations for Authors

4.1. Publishing in taxonomy needs to be in compliance with the nomenclatural codes

It is highly recommended to publish in a journal with an ISSN (International Standard Serial Numbers) archived in a LOCKSS system ("Lots Of Copies Keep Stuff Safe"), or equivalent, archiving the article in a PDF/A format and providing either Zoobank or Mycobank registrations numbers, and in the future, for plants, one from the accepted registration system(s) put in place under the ICN.

\section{Recommendations regarding OA}

A) Recommendations from the institutional and/or the community point of view

Recommendation 5. Promote $\mathrm{OA}$ in your institution

5.1. Promote publication in Gold $\mathrm{OA}$ by default, i.e., online publication of an article edited by a scientific publisher, to produce an official final paper (with peer review, revision, copy editing, layout, verification of all details: nomenclature, DOI, bibliographical references, etc.).

5.2. Develop a clear policy for $\mathbf{O A}$ and give your researchers the help and means to deposit a digital copy of their articles in an institutional or national repository (Green OA).

5.3. Fight against excessive APCs, invite authors to publish in fair-priced online journals and put a limit on how much authors may delve into their grants or institutional budgets for APCs. For instance, in some European countries, it is ca. 1,300 Euro/article in taxonomy-related fields (in taxonomy, for a rate of 20 Euro/page a budget of 800 Euros for 40 pages is necessary).

5.4. Promote the institutional publications, regain or maintain control of publishing in-house or within a consortium supporting fair publishing practices (e.g., the European Journal of Taxonomy).

5.5. Evaluate researchers accordingly with the institutional $O A$ policy. The evaluation should take into account the fact that the articles have been published in OA, for a focus placed on those in Diamond OA.

In the specific case of the CETAF membership, journals published by learned societies or associations hosted by the CETAF member institutions can benefit from the CETAF Publishing working group to help them to comply with their institution OA policy or to transform their economic model into a model that is both sustainable and compliant.

B) Recommendations to authors

Recommendation 6. Publish in Open Access journals following the recommendations below: 
6.1. Select high-quality journals with an impact factor, but most importantly journals promoting a fair model for OA or, even better, publishing in Diamond OA (such as the European Journal of Taxonomy).

6.2. Do not post pre-print or post-print articles online on platforms or networks as this might invalidate taxonomic acts or complicate their later interpretation.

6.3. Posting your article on ResearchGate, Academia, etc. does not qualify as $\mathrm{OA}$ and most of the time it is forbidden by the commercial publishers. Moreover, major publishing companies are currently taking action against ResearchGate's copyright infringements. Thus, special attention must be given to the legality of online diffusion on these networks.

6.4. Submit a copy of the publisher's final document in PDF to your institution's repository (archiving) as soon as it is possible, it may even be mandatory depending on the funding source, institution and country. Institutes or universities generally have an obligation to do so.

\subsection{If your article could not be published in Gold OA:}

- check SHERPA RoMEO for the date of the release of an article from the embargo (an embargo period is generally 6 months in the taxonomy related fields);

- during the embargo period, respond to requests for PDFs face-to-face (generally allowed by publishers; see conditions in SHERPA RoMEO);

- provide article access as soon as possible via an online repository (Green Road);

- always give precedence to the publisher's final PDF (not a post-print, and certainly not a pre-print).

\section{Acknowledgements}

This paper was drafted after the notes by Patricia Mergen and Chloé Besombes during the two CETAF workshops, to whom the authors are thankful. We are grateful to the reviewers, Gildas Illien, Koen Martens and Philippe Bouchet, for their remarks and valuable comments on an earlier version of the manuscript that helped us to improve it. The authors would also like to thank the CETAF community for its active participation to the workshops which led to this paper and all the colleagues, scientists, librarians and desk-editors, who provided beneficial remarks and useful corrections. A big special thank you to the EJT team, and in particular Chloë Chester and Kristiaan Hoedemakers, whose patience and professionalism allowed the publication of this article.

\section{References}

Ardenghi N.M.G., Barcheri G., Ballerini C., Cauzzi P. \& Guzzon F. 2016. Gymnocoronis spilanthoides (Asteraceae, Eupatorieae), a new naturalized and potentially invasive aquatic alien in $\mathrm{S}$ Europe. Willdenowia 46: 265 -273. https://doi.org/10.3372/wi.46.46208

Bethesda Statement on Open Access Publishing 2003.

Available from http://legacy.earlham.edu/ peters/fos/bethesda.htm [accessed 5 Nov. 2018].

Berlin Declaration on Open Access to Knowledge in the Sciences and Humanities 2003. Available from https://openaccess.mpg.de/Berlin-Declaration [accessed 5 Nov. 2018].

Bouchet P., Bary S., Héros V. \& Marani G. 2016. How many species of molluscs are there in the world's oceans and who is going to describe them? In: Héros V., Strong E. \& Bouchet P. (eds) Tropical Deep-Sea Benthos 29. Mémoires du Muséum national d'Histoire naturelle 208: 9-24, Muséum national d'Histoire naturelle, Paris. 
BÉNICHOU L. et al., Best practices in electronic publishing in taxonomy

Bouchout Declaration: A contribution from the biodiversity community to Open Digital Science 2014. Available from https:/ec.europa.eu/digital-single-market/en/news/bouchout-declaration-contributionbiodiversity-community-open-digital-science [accessed 5 Nov. 2018].

Budapest Open Access Initiative Declaration 2002.

Available from http://www.budapestopenaccessinitiative.org [accessed 5 Nov. 2018].

European Commission, Directorate-General for Research \& Innovation 2017. H2020 Programme Guidelines to the Rules on OA to Scientific publications and OA to Research Data in Horizon 2020, version 3.2 21 March 2017. Available online.

Cabut S. \& Larousserie D. 2013. À qui appartient le savoir ? Le Monde Science et Techno. Available from https://www.lemonde.fr/sciences/article/2013/02/28/a-qui-appartient-le-savoir_1840797_1650684.html [accessed 5 Nov.2018].

Coritico F.P., Amoroso V.B. \& Lehnert M. 2017. New records, names and combinations of scaly tree ferns (Cyatheaceae) in eastern Malesia. Blumea 62: 92-96. https://doi.org/10.3767/blumea.2017.62.02.03

Earney L. 2017. Offsetting and its discontents: challenges and opportunities of open access offsetting agreements. Insights 30 (1): 11-24. https://doi.org/10.1629/uksg.345

Foley N.M., Goodman S.M., Whelan C.V., Puechmaille S.J. \& Teeling E. 2017. Towards navigating the minotaur's labyrinth: cryptic diversity and taxonomic revision within the speciose genus Hipposideros (Hipposideridae). Acta Chiropterologica 19 (1): 1-18.

https://doi.org/10.3161/15081109ACC2017.19.1.001

Fontaine B., Perrard A. \& Bouchet P. 2012. 21 years of shelf life between discovery and description of new species. Current Biology 22 (22): 1-2. https://doi.org/10.1016/j.cub.2012.10.029

Gargouri Y., Hajjem C., Larivière V., Gingras Y., Carr L., Brody T. \& Harnad S. 2010. Self-selected or mandated, Open Access increases citation impact for higher quality research. PlosOne 5 (10): 1-12. https://doi.org/10.1371/journal.pone.0013636

ICZN 1999. International Code of Zoological Nomenclature, 4th Edition. London, UK: International Trust for Zoological Nomenclature. Available from http://iczn.org/iczn/index.jsp [accessed 5 Nov. 2018].

ICZN 2012. Amendment of Articles 8, 9, 10, 21 and 78 of the International Code of Zoological Nomenclature to expand and refine methods of publication. Bulletin of Zoological Nomenclature 69 (3): 161-169. Available from http://iczn.org/content/iczn-amendment-electronic-publication [accessed 5 Nov. 2018].

Jahn R., Kusber W.-H. \& Cocquyt C. 2017. Differentiating Iconella from Surirella (Bacillariophyceae): typifying four Ehrenberg names and a preliminary checklist of the African taxa. PhytoKeys 82: 73-112. https://doi.org/10.3897/phytokeys.82.13542

Johnson R., Watkinson A. \& Mabe M. 2018. The STM Report. An Overview of Scientific and Scholarly Publishing. 1968-2018. Association of Scientific, Technical and medical Publishers, The Hague.

Jussieu Call for Open Science and Bibliodiversity 2016. Available from https://jussieucall.org/jussieu-call/ [accessed 5 Nov. 2018].

Kim S., Heppner J.B. \& Park K.-T. 2017. Eight new species of the genus Promalactis (Lepidoptera: Oecophoridae) from Indonesia, with a checklist of the genus. Journal of Natural History 51 (29-30): 1671-1695. https://doi.org/10.1080/00222933.2017.1353154

Knapp S., Sagona E., Carbonell A.K.Z. \& Chiarini F. 2017. A revision of the Solanum elaeagnifolium clade (Elaeagnifolium clade; subgenus Leptostemonum, Solanaceae). PhytoKeys 84: 1-104. https://doi.org/10.3897/phytokeys.84.12695 
Kottelat M. 2015. Fried spicy Linnaeus-the consequences of indiscriminate citation of authors of scientific names. Zootaxa 3936 (1): 147-150. https://doi.org/10.11646/zootaxa.3936.1.10

Lanteri A.A. \& del Río M.G. 2017. Naupactus xanthographus (Germar) species group (Curculionidae: Entiminae: Naupactini): a comprehensive taxonomic treatment. Journal of Natural History 51 (27-28): $1557-1587$.

Meier R. 2017. Citation of taxonomic publications: the why, when, what and what not. Systematic Entomology 42: 301-304. https://doi.org/10.1111/syen.12215

Mendoza-Garfias B., García-Prieto L. \& Pérez-Ponce de León G. 2017. Checklist of the Monogenea (Platyhelminthes) parasitic in Mexican aquatic vertebrates. Zoosystema 39 (4): 501-598. https://doi.org/10.5252/z2017n4a5

Moedas C. \& Dekker S. 2015. Call on scientific publishers to adapt their business models to new realities. Available from https:/ec.europa.eu/commission/commissioners/2014-2019/moedas/announcements/ commissioner-moedas-and-secretary-state-dekker-call-scientific-publishers-adapt-their-business_en [accessed 5 Nov. 2018].

Musavu Moussavou B. 2017. Systematics, palaeoecology and taphonomy of Turonian oysters from the northern Gabon Coastal Basin. Geodiversitas 39 (2): 213-224. https://doi.org/10.5252/g2017n2a3

OpCit project website. 2013. The Effect of Open Access and Downloads ('Hits') on Citation Impact: a Bibliography of Studies. Available from http://opcit.eprints.org/oacitation-biblio.html [accessed 5 Nov. 2018].

Páll-Gergely B. 2014. Suggestions to improve the Taxonomy Index (T-Index) introduced by Valdecasas (2011). Zootaxa 3780 (2): 399-400. https://doi.org/10.11646/zootaxa.3780.2.11

Pole M. \& McLoughlin S. 2017. The first Cenozoic Equisetum from New Zealand. Geobios 50: 259265. https://doi.org/10.1016/j.geobios.2017.04.001

Rakotondrainibe F. \& Jouy A. 2016. Révision du genre Deparia Hook. \& Grev. (Pteridophyta, Athyriaceae) à Madagascar: trois espèces nouvelles, une synonymie nouvelle et des hybrides présumés. Candollea 71 (12): 357-371. https://doi.org/10.15553/c2016v712a18

Schott R.K. \& Evans D.C. 2016. Cranial variation and systematics of Foraminacephale brevis gen. nov. and the diversity of pachycephalosaurid dinosaurs (Ornithischia: Cerapoda) in the Belly River Group of Alberta, Canada. Zoological Journal of the Linnean Society 2016: 1-42. https://doi.org/10.1111/zoj.12465

Seifert K.A., Crous P.W. \& Frisvad J.C. 2008. Correcting the impact factors of taxonomic journals by appropriate citation of taxonomy (ACT). Persoonia 20: 105.

Solow A.R., Mound L.A. \& Gaston K.J. 1995 Estimating the rate of synonymy. Systematic Biology 44 (1): 93-96. Available from www.jstor.org/stable/2413485 [accessed 5 Nov. 2018].

Suber P. 2012. OA. MIT Press (Essential Knowledge Series), Cambridge, MA/London, UK.

Swan A. 2006. OA: What is it and why should we have it?

Available from https://eprints.soton.ac.uk/263028/1/AS-OA-final.pdf [accessed 5 Nov. 2018].

Thomaz S.M. \& Martens K. 2009. Opinion: alternative metrics to measure journal impacts: entering in a "free market" era. Hydrobiologia 636: 7-10.

Tucker S.J., Kurniasih E.M. \& Craig M.T. 2016. A new species of grouper (Epinephelus; Epinephelidae) from the Indo-Pacific. Copeia 104 (3): 658-662. https://doi.org/10.1643/CI-16-398 
BÉNICHOU L. et al., Best practices in electronic publishing in taxonomy

Turland N.J., Wiersema J.H., Barrie F.R., Greuter W., Hawksworth D.L., Herendeen P.S., Knapp S., Kusber W.-H., Li D.-Z., Marhold K., May T.W., McNeill J., Monro A.M., Prado J., Price M.J. \& Smith G.F. (eds) 2018. International Code of Nomenclature for Algae, Fungi, and Plants (Shenzhen Code) adopted by the Nineteenth International Botanical Congress Shenzhen, China, July 2017. Regnum Vegetabile 159. Koeltz Botanical Books, Glashütten. https://doi.org/10.12705/Code.2018

Valdecasas A.G. 2011. An index to evaluate the quality of taxonomic publications. Zootaxa 2925: 57-62

Valdecasas A.G. 2014. A reply to Páll-Gergely's suggestions to improve the taxonomy index (T-Index) introduced by Valdecasas (2011).Zootaxa 3784 (1): 099-100. https://doi.org/10.11646/zootaxa.3784.1.10

Wägele H., Klussmann-Kolb A., Kuhlmann M., Haszprunar G., Lindberg D., Koch A. \& Wägele J.W. 2017. The taxonomist - an endangered race. A practical proposal for its survival. Frontiers in Zoology 2011 (8): 1-7. https://doi.org/10.1186/1742-9994-8-25

Waite R. \& Allmon W.D. 2016. Observations on the biology and sclerochronology of "turritella" duplicata (Linnaeus, 1758) (Cerithioidea, Turritellidae) from southern Thailand. Malacologia 59 (2): 247-269.

Wang X., Liu C., Mao W. \& Fang Z. 2015. The open access advantage considering citation, article usage and social media attention. Scientometrics 103 (2): 555-564. https://doi.org/10.1007/s11192-015-1547-0

Werner Y.L. 2006. The case of impact factor versus taxonomy: a proposal. Journal of Natural History 40 (21-22): 1285-1286. https://doi.org/10.1080/00222930600903660

Yu M.-C., Kolbasov G., Hosie A.M., Lee T.M. \& Chan B.K.K. 2017. Descriptions of four new sponge-inhabiting barnacles (Thoracica: Archaeobalanidae: Acastinae). Zootaxa 4277 (2): 151-198 https://doi.org/10.11646/zootaxa.4277.2.1

Manuscript received: 23 October 2018

Manuscript accepted: 4 November 2018

Published on: 13 November 2018

Topic editor: Koen Martens

Desk editor: Chloë Chester \& Kristiaan Hoedemakers

Printed versions of all papers are also deposited in the libraries of the institutes that are members of the EJT consortium: Muséum national d'Histoire naturelle, Paris, France; Meise Botanic Garden, Belgium; Royal Museum for Central Africa, Tervuren, Belgium; Natural History Museum, London, United Kingdom; Royal Belgian Institute of Natural Sciences, Brussels, Belgium; Natural History Museum of Denmark, Copenhagen, Denmark; Naturalis Biodiversity Center, Leiden, the Netherlands; Museo Nacional de Ciencias Naturales-CSIC, Madrid, Spain; Real Jardín Botánico de Madrid CSIC, Spain; Zoological Research Museum Alexander Koenig, Bonn, Germany. 